\title{
The Effect of Microwave-Vacuum Pretreatment on the Drying Kinetics, Color and the Content of Bioactive Compounds in Osmo-Microwave-Vacuum Dried Cranberries (Vaccinium macrocarpon)
}

\author{
Magdalena Zielinska $^{1,2} \cdot$ Danuta Zielinska $^{1,2} \cdot$ Marek Markowski $^{1,2}$
}

Received: 26 May 2017 / Accepted: 20 November 2017 / Published online: 29 November 2017

(C) The Author(s) 2017. This article is an open access publication

\begin{abstract}
The aim of this study was to compare the effectiveness of microwave-vacuum pretreatment conducted at 100,500 and $800 \mathrm{~W}$ on the drying kinetics of whole cranberries (Vaccinium macrocarpon) during hybrid osmotic and microwave-vacuum drying. Additionally, the effect of microwave-vacuum pretreatment and subsequent osmo-microwave-vacuum drying on selected quality indicators of dried cranberries, including phenolic content, antioxidant activity and color, was studied, and the quality of samples was compared with freeze dried, microwave-vacuum dried and osmo-microwave-vacuum dried samples. Irrespective of microwave power, the initial pretreatment accelerated mass transfer during osmotic dehydration of cranberries, and the Weibull model well fitted the experimental data. Final microwave-vacuum drying of cranberries was a two-stage process involving a relatively long phase with a constant drying rate, followed by a short period with a decreasing drying rate. Microwave-vacuum and osmomicrowave-vacuum drying resulted in similar retention of polyphenols and similar antioxidant activity, both of which were relatively higher than in freeze-dried cranberries. However, microwave-vacuum pretreatment at low microwave power $(100 \mathrm{~W})$ before dehydration also resulted in high retention of phenolic compounds, high antioxidant activity and attractive color, which were consistent with the high content of total anthocyanins and flavonoids. Microwave-vacuum, osmo-microwave-vacuum and osmo-microwave-vacuum drying combined with microwave-vacuum pretreatment at low microwave power $(100 \mathrm{~W})$ were the most suitable methods for the production of high-quality dried whole cranberries.
\end{abstract}

Keywords Vaccinium macrocarpon - Osmotic dehydration - Microwave-vacuum drying · Mathematical modeling · Physico-chemical properties

\section{Introduction}

Cranberries are a rich source of physiological and phytochemical nutrients. They contain more than 150 nutrients and bioactive compounds, including phenolic compounds, vitamins, organic acids and fibers (Pappas and Schaich 2009). Polyphenols, mainly phenolic acids, are the most valuable group of bioactive compounds in cranberry fruit which exhibit

Magdalena Zielinska

m.zielinska@uwm.edu.pl

1 Department of Systems Engineering, University of Warmia and Mazury in Olsztyn, Olsztyn, Poland

2 Department of Chemistry, University of Warmia and Mazury in Olsztyn, Olsztyn, Poland strong antioxidant properties. Anthocyanins, flavonoids that are primarily responsible for the red, pink and purple color of cranberries, have been also widely studied due to their antioxidant potential (Côté et al. 2010).

Despite their outstanding health-promoting properties, cranberries are rarely consumed fresh due to their sour, tart and astringent taste. For this reason, cranberries are usually processed into sweetened juices (Alasalvar and Shahidi 2013). However, there is extensive evidence to demonstrate that processing leads to significant loss of polyphenols, in particular anthocyanins (White et al. 2011). Hot air drying is the most popular drying method due to low cost. The main disadvantage of hot air drying is long drying time which is mainly due to the presence of a natural waxy surface layer that obstructs heat and mass transfer. Long drying time may lead to significant material shrinkage due to mechanical stress, damage to 
cytoplasmic membranes and concentrations of dry matter components (Tonon et al. 2010). High temperature, air exposure and cell damage have to be controlled during the drying process to preserve polyphenols in dried cranberries (Howard et al. 2012). Heat may also induce oxidation (including phenolic browning), isomerization (e.g., epimerization of catechins) and loss of the gallate group attached to the C-ring of flavonoids (Wojdylo et al. 2009). The moisture present during heating (including in early stages of dehydration) accelerates hydrolysis and dimerization (Tonon et al. 2010; Chamorro et al. 2012).

The growing popularity of dried berries has increased the demand for effective drying methods that preserve the bioactive properties and health benefits of cranberries. Unlike hot air drying, freeze drying is particularly effective in preserving bioactive compounds in fruit (Sogi et al. 2013). Freeze drying is generally recommended for fruits and vegetables containing heat-sensitive antioxidant components such as tocopherols, ascorbic acid, carotenoids and plant phenols (Shofian et al. 2011). Vacuum drying methods minimize the loss of anthocyanins, ellagic acid, flavonols and ascorbic acid in comparison with hot air drying, while microwave-vacuum drying exerts even more protective effects on the processed foods (Wojdylo et al. 2009). To eliminate the disadvantages of hot air drying (high temperature, air exposure, long drying time) and freeze drying (long drying time, high operational cost), new combinations of processing methods that decrease heat, drying time, air exposure and preserve the nutritional value of dried fruit have been developed to cater to the needs of health-conscious consumers. Microwave-vacuum drying is characterized by relatively short drying time and low temperature, and it can be used to produce high-quality dried products (Wojdylo et al. 2009; Kwok et al. 2004; Scaman and Durance 2005). The physical phenomena that occur during microwave drying are difficult to model in foods with a high moisture content (Kowalski et al. 2010), and the resulting drying models are not easy to use. An alternative approach based on empirical or semi-empirical models has been proposed to differentiate between different drying phases and to calculate moisture diffusivity.

The existing pretreatments for cranberry drying rely on mechanical (halving, slicing or perforation), chemical (ethyl oleate, sodium hydroxide) and thermal (freezing/thawing, blanching in steam or water) methods (Grabowski et al. 2007).

Osmotic dehydration is often used to partially remove moisture from berries before further processing. To date, osmotic dehydration has been successfully used to preserve various fruits and vegetables, including bananas, pineapples, mangoes and leafy vegetables (Pokharkar and Prasad 1998). Similarly to hot air drying, mass transfer is very slow during osmotic dehydration of cranberries, and moisture removal is impeded by thick skin and the natural wax surface layer. The content of total anthocyanins and phenolic compounds may also decrease significantly during osmotic dehydration of berries in a sucrose solution. Osmo-convective drying of berries may induce an even greater loss of bioactive compounds due to oxidation and thermal degradation (Lohachoompol et al. 2004). Nevertheless, this method is preferred over other drying techniques because it prolongs the products' shelf life, lowers energy consumption and delivers dried products with unique texture and improved sensory acceptability. Moisture removal decreases the sample load for finish-drying, drying times and overall costs. Additionally, osmotic dehydration increases the solids content of the final product (Ramaswamy and Tola 2014). In recent years, much attention has been paid to pretreatment methods and methods that are applied during osmotic dehydration to increase mass transfer between the dried material and the osmotic solution. Various pretreatments that can be used before (freezing/ thawing, blanching, pulsed electric field) or during osmotic dehydration (ultrasounds, gamma-irradiation, vacuum, centrifugal force, high pressure) have been proposed (Amami et al. 2005; Knorr et al. 2000; Rastogi et al. 2002; Knorr 2003). Preliminary freezing/thawing facilitates heat and mass transfer by significantly decreasing the thickness and mechanical strength of skin, and it and may be effectively used as a pretreatment method (Zielinska et al. 2015). Recent years have witnessed the growing popularity of microwave pretreatments applied before or during osmotic dehydration as an alternative to conventional methods (Wray and Ramaswamy 2015). Wray and Ramaswamy (2015) developed a novel drying method for whole cranberries which involves (i) microwave-assisted osmotic dehydration pretreatment under continuous flow medium spray conditions, coupled with (ii) finish microwave-vacuum drying. The proposed method preserves product quality more effectively than air drying, and it approximates the standards set by freeze-drying. Microwave-vacuum pretreatments that combine the advantages of microwave drying, eliminate the drawbacks of conventional processing methods and rely on reduced pressure during microwave drying eliminate the risk of excessive temperature and degradation of heat-sensitive bioactive compounds (Cui et al. 2012). Conventional drying methods and emerging food processing technologies, such as drying, extraction, baking, roasting, pasteurization/sterilization and tempering, are coupled with microwave methods to increase mass transfer, shorten processing time, reduce costs and improve product quality (Ekezie et al. 2017). However, there is a lack of scientific research on microwave-vacuum pretreatment, its effect on mass transfer during hybrid osmotic and microwaveassisted drying, and the quality of whole cranberries (Vaccinium macrocarpon).

Empirical, semi-empirical, mechanistic and phenomenological models have been proposed in the literature to predict the mass transfer kinetics during osmotic dehydration of food products (Assis et al. 2016). Azuara, Peleg, Page and Weibull 
empirical models have been applied to correlate process variables with water loss (WL) and solids gain (SG) (KaymakErtekin and Sultanoglu 2000; Azuara et al. 1992; HermanLara et al. 2013; Mercali et al. 2011; Sereno et al. 2001). The semi-empirical models have been derived from the analytical modes developed by Crank (1975) for moisture diffusion within a homogeneous and isotropic sphere of a slabshaped product (Assis et al. 2016). These models support the determination of moisture or solids diffusion coefficients during reverse processes of moisture loss and solids gain in osmotically dehydrated fruits or vegetables (Herman-Lara et al. 2013; Mercali et al. 2011).

In the present study, a novel method for drying whole cranberries with the involvement of (i) osmotic dehydration preceded by freezing/thawing and microwave-vacuum pretreatment, coupled with (ii) finish microwave-vacuum drying has been proposed. Initial freezing/thawing and microwave-vacuum pretreatment as well as osmotic dehydration followed by final microwave-vacuum drying may be cost- and time-effective techniques for processing berries. Fruit can be freeze-stored before the drying experiment. Osmotic dehydration may be used as a partial dehydration method on account of its low cost. Osmotic dehydration increases the solids content of dried products and improves the sensory acceptability of cranberries which are sour in taste and unacceptable to consumers when fresh. Freezing/thawing can be applied to increase mass transfer during dehydration (Zielinska et al. 2015). Microwavevacuum treatments produce surface microcracks, and they can also be deployed to improve moisture transfer during osmotic dehydration (Zielinska et al. 2015). Final microwave-vacuum drying can replace commercial hot air drying to shorten drying time. Microwave-vacuum drying of whole cranberries shortens drying time by $94 \%$ in comparison with hot air drying (Zielinska et al. 2017). When applied in combination, the above methods are likely to produce whole dried cranberries with high concentrations of bioactive compounds.

Therefore, the aim of this study was to compare the effectiveness of microwave-vacuum pretreatment (at 100,500 and $800 \mathrm{~W}$ ) on the drying kinetics of whole cranberries (Vaccinium macrocarpon) during hybrid osmotic and microwave-vacuum drying, and to compare the induced physical and chemical changes to determine the optimal recovery of bioactive compounds. Cranberries were analyzed for their total phenolic content, total flavonoid content and total content of monomeric anthocyanins, antioxidant activity, and color parameters $L^{*}, a^{*}$ and $b^{*}$. Osmotic dehydration and microwave-vacuum drying of whole cranberries were described mathematically, and the values of effective moisture diffusivity $\left(\mathrm{D}_{\mathrm{eM}}\right)$ and solids diffusivity $\left(\mathrm{D}_{\mathrm{eS}}\right)$ were calculated.

\section{Materials and Methods}

\section{Materials}

Fresh cranberries (Vaccinium macrocarpon L.) were obtained from a local farm (Lublin region, Poland). Whole cranberries were packed in sealed plastic containers several hours after harvest. Fresh fruit were free from disease or discoloring and were similar in freshness and size. Cranberries were refrigerated $\left(2 \pm 2{ }^{\circ} \mathrm{C}\right)$ at $90 \%$ relative humidity for up to 2 weeks.

\section{Pretreatment of Whole Cranberries}

Fresh cranberries were subjected to freezing/thawing pretreatment $(\mathrm{F})$. Freezing time was $24 \mathrm{~h}$, and freezing temperature was $-18{ }^{\circ} \mathrm{C}$. Thawing time was $24 \mathrm{~h}$, and thawing temperature was $21^{\circ} \mathrm{C}$. Pretreated cranberries were divided into two groups. The first group was subjected to osmotic dehydration and final microwave-vacuum drying, and the second group was subjected to microwave-vacuum pretreatment before combined osmotic dehydration and final microwave-vacuum drying. The test stand was composed of a motor, control valve, condensation unit, drying chamber equipped with a pyrometer for temperature measurements, microwave generator, microwave circulator, vapor pressure measuring unit and a control unit (Promis Tech, Wroclaw, Poland). Moisture content was determined at $9.72 \pm 0.02 \mathrm{~kg} \mathrm{H}_{2} \mathrm{O} / \mathrm{kg} \mathrm{DM}$ in frozen/thawed berries, and at $7.73 \pm 0.02 \mathrm{~kg} \mathrm{H}_{2} \mathrm{O} / \mathrm{kg} \mathrm{DM}$ to $7.85 \pm 0.03 \mathrm{~kg}$ $\mathrm{H}_{2} \mathrm{O} / \mathrm{kg}$ DM in microwave-vacuum treated samples. The soluble solids content of frozen/thawed berries was $9.12 \pm$ $0.02 \%$. The mass of cranberries used in each drying experiment was $0.150 \pm 0.001 \mathrm{~kg}$. Three combinations of microwave power and processing time were applied before osmotic dehydration. Microwave-vacuum drying was conducted at microwave power of 100,500 and $800 \mathrm{~W}$ (M1, M5, M8) which is equivalent to microwave power density of $0.67 \pm$ $0.01,3.33 \pm 0.01$ and $5.33 \pm 0.01 \mathrm{~W} / \mathrm{g}$, respectively. Treatment time was $1.50 \pm 0.08$ to $20.00 \pm 0.08 \mathrm{~min}$, depending on microwave power density. Cranberries were subjected to low microwave power to keep their temperature below 40 $\pm 1{ }^{\circ} \mathrm{C}$. The absolute pressure in the drying chamber was $5 \pm$ $1 \mathrm{kPa}$. The rotational speed of the drying chamber was $6 \mathrm{rpm}$. The experimental design for the microwave-vacuum pretreatment of cranberries is shown in Table 1.

\section{Osmotic Dehydration of Whole Cranberries}

Cranberries were subjected to osmotic dehydration $(\mathrm{O})$ treatment in a water bath (LWT 6/150, WSL, Poland) filled with sucrose solution. The sucrose solution had a concentration of $65^{\circ} \mathrm{Brx}$ and temperature of $21 \pm 1^{\circ} \mathrm{C}$. The sample to solution ratio was 1: 4 in all experiments. Osmotic dehydration was conducted for $6 \mathrm{~h}$ under constant conditions. Dehydration 
Table 1 Experimental design for initial microwave vacuum pretreatment of cranberries

\begin{tabular}{lllllll}
\hline Sample & $\begin{array}{l}\mathrm{MC}_{1} \\
{\left[\mathrm{~kg} \mathrm{H} \mathrm{H}_{2} \mathrm{O} / \mathrm{kg} \mathrm{DM}\right]}\end{array}$ & $\mathrm{MW}[\mathrm{W} / \mathrm{g}]$ & $\mathrm{P}[\mathrm{kPa}]$ & $t[\mathrm{~min}]$ & $T_{\text {Max }}\left[{ }^{\circ} \mathrm{C}\right]$ & $\begin{array}{l}\mathrm{MC}_{2} \\
{\left[\mathrm{~kg} \mathrm{H} \mathrm{H}_{2} \mathrm{O} / \mathrm{kg} \mathrm{DM}\right.}\end{array}$ \\
\hline FM1 & $9.72 \pm 0.02^{\mathrm{a}}$ & $0.67 \pm 0.01^{\mathrm{a}}$ & $5 \pm 1^{\mathrm{a}}$ & $20.00 \pm 0.08^{\mathrm{a}}$ & $40 \pm 1^{\mathrm{a}}$ & $7.85 \pm 0.03^{\mathrm{a}}$ \\
FM5 & $9.72 \pm 0.02^{\mathrm{a}}$ & $3.33 \pm 0.01^{\mathrm{b}}$ & $5 \pm 1^{\mathrm{a}}$ & $1.75 \pm 0.08^{\mathrm{b}}$ & $37 \pm 1^{\mathrm{b}}$ & $7.73 \pm 0.02^{\mathrm{b}}$ \\
FM8 & $9.72 \pm 0.02^{\mathrm{a}}$ & $5.33 \pm 0.01^{\mathrm{c}}$ & $5 \pm 1^{\mathrm{a}}$ & $1.50 \pm 0.08^{\mathrm{c}}$ & $37 \pm 1^{\mathrm{b}}$ & $7.84 \pm 0.02^{\mathrm{a}}$ \\
\hline
\end{tabular}

Table shows the mean values \pm standard errors

$\mathrm{MC}_{1}$ — moisture content of frozen cranberries, $\mathrm{kg} \mathrm{H}_{2} \mathrm{O} / \mathrm{kg} \mathrm{DM}$; MW—-microwave power density, W/g; $\mathrm{P}$ — drying chamber pressure, $\mathrm{kPa}$; $\mathrm{t}$-time of treatment, min; $\mathrm{T}_{\mathrm{Max}}$ - material maximum temperature, ${ }^{\circ} \mathrm{C} ; \mathrm{MC}_{2}-$ moisture content of initially treated cranberries, $\mathrm{kg} \mathrm{H}_{2} \mathrm{O} / \mathrm{kg} \mathrm{DM}$

FM1 - frozen cranberries subjected to microwave vacuum pretreatment at microwave power of $100 \mathrm{~W}$; FM5frozen cranberries subjected to microwave vacuum pretreatment at microwave power of $500 \mathrm{~W}$; FM8 - frozen cranberries subjected to microwave vacuum pretreatment at microwave power of $800 \mathrm{~W}$ experiments were replicated, and the average values of two replications were taken.

\section{Final Microwave-Vacuum Drying of Whole Cranberries}

After osmotic dehydration, cranberries were subjected to final microwave-vacuum drying (MWVD) (Promis Tech, Wroclaw, Poland). The MWVD method has been described in detail elsewhere (Zielinska et al. 2013). The mass of cranberries used in each drying experiment was $0.150 \pm 0.003 \mathrm{~kg}$. Microwave power was set at $100 \mathrm{~W}$ (M1), microwave power density was $0.67 \pm 0.01 \mathrm{~W} / \mathrm{g}$, and absolute pressure in the drying chamber was $5 \pm$ $1 \mathrm{kPa}$. The rotational speed of the drying chamber was $6 \mathrm{rpm}$. The drying time of every successive batch of raw cranberries was increased to determine mass loss. Each time, cranberries were dried to a final moisture content below $0.17 \pm 0.02 \mathrm{~kg} \mathrm{H}_{2} \mathrm{O} / \mathrm{kg} \mathrm{DM}$. The drying process was stopped when the temperature of the dried material increased suddenly and there were no changes in sample mass. The drying chamber was equipped with a pyrometer to control the temperature of cranberries during drying. The drying experiments were conducted in duplicate.

\section{Determination of Moisture Loss and Solids Gain}

A separate experiment was conducted to evaluate moisture loss and solids gain. Each sample was removed from the osmotic solution, rinsed with deionized water, blotted with blotting paper and weighed. The moisture content and solids content of frozen and osmotically dehydrated cranberries were determined gravimetrically in the DZ ZBC II vacuum drying oven (Chemland, Stargard Szczeciński, Poland). The samples were dried at $70{ }^{\circ} \mathrm{C}$ for $24 \mathrm{~h}$. The samples were weighed to the nearest $0.0001 \mathrm{~g}$ on the XA/60/220/X analytical balance (Radwag, Radom, Poland).
Moisture loss (g/100 $\mathrm{g}$ fresh fruit $)$ and solids gain $(\mathrm{g} / 100 \mathrm{~g}$ fresh fruit) were calculated based on the following mass balance equations (Souraki et al. 2012):

$$
\begin{aligned}
& \mathrm{ML}_{\mathrm{t}}=\frac{\left(W_{0}-W_{t}\right)+\left(S_{t}-S_{0}\right)}{W_{0}} \cdot 100 \\
& \mathrm{~S}_{\mathrm{t}}=\frac{\left(S_{t}-S_{0}\right)}{W_{0}} \cdot 100
\end{aligned}
$$

where: $W_{0}$ is the initial weight of cranberries $(\mathrm{g}), S_{0}$ is the initial content of dry solids in cranberries $(\mathrm{g}), W_{t}$ is the weight (g) and $S_{t}$ is the content of dry solids in cranberries osmotically dehydrated over time $t$.

\section{Modeling Mass Transfer During Osmotic Dehydration of Whole Cranberries}

The Weibull model was used to describe complex mass transfer processes during osmotic dehydration of cranberries. Partial moisture loss and solids gain during osmotic dehydration was expressed as (Cunha et al. 1998):

$$
\begin{aligned}
\frac{\mathrm{ML}}{\mathrm{ML}_{\infty}} & =1-\exp \left[-\left(\frac{\mathrm{t}}{\alpha_{\mathrm{M}}}\right)^{\beta_{\mathrm{M}}}\right] \\
\frac{\mathrm{SG}}{\mathrm{SG}_{\infty}} & =1-\exp \left[-\left(\frac{\mathrm{t}}{\alpha_{\mathrm{S}}}\right)^{\beta_{\mathrm{S}}}\right]
\end{aligned}
$$

where $\alpha$ is the scale parameter associated with the process rate, and $\beta$ is the shape parameter.

The reaction kinetics of growth/decay are described by a first-order model for $\beta=1$. The failure rate for the Weibull model is a function that increases over time for $\beta>1$ and decreases over time for $\beta<1$. When $\beta=1$, the failure rate is constant. The scale parameter $\alpha$ is a characteristic time to failure, as it corresponds to the $100 *(1-1 / \mathrm{e})=63.2$ percentile 
of the distribution, regardless of the value of $\beta$ (Gacula and Kubala 1975).

\section{Determination of Effective Moisture Diffusivity and Solids Diffusivity During Osmotic Dehydration of Whole Cranberries}

The shape of cranberries is not a perfect sphere, but an ellipsoid with an axis of symmetry axis parallel to the longest axis of an ellipsoid. In our preliminary study, the sphericity coefficient of berries was determined at minimum 0.9. Therefore, the model was developed on the assumption that berries are spherical in shape. We also observed that the shrinkage of cranberries was considerably lower during osmotic dehydration than hot-air conventional drying. The above can be attributed to the fact that moisture loss is accompanied by solids gain during osmotic dehydration. Therefore, shrinkage phenomena were not taken into account during modeling. The moisture loss ratio (MR) and the solids gain ratio (SR) of cranberries as a function of dehydration time were expressed using the following formulas (Crank 1975):

$\mathrm{MR}=\frac{\mathrm{ML}_{\infty}-\mathrm{ML}_{\mathrm{t}}}{\mathrm{ML}_{\infty}-\mathrm{ML}_{0}}=\frac{6}{\pi^{2}} \sum_{\mathrm{n}=1}^{\infty} \frac{1}{\mathrm{n}^{2}} \exp \left(-\mathrm{n}^{2} \pi^{2} \frac{\mathrm{D}_{\mathrm{eM}} \mathrm{t}}{\mathrm{R}^{2}}\right)$

$\mathrm{SR}=\frac{\mathrm{SG}_{\infty}-\mathrm{SG}_{\mathrm{t}}}{\mathrm{SG}_{\infty}-\mathrm{SG}_{0}}=\frac{6}{\pi^{2}} \sum_{\mathrm{n}=1}^{\infty} \frac{1}{\mathrm{n}^{2}} \exp \left(-\mathrm{n}^{2} \pi^{2} \frac{\mathrm{D}_{\mathrm{es}} \mathrm{t}}{\mathrm{R}^{2}}\right)$

where: $\mathrm{ML}_{\infty}$ is moisture loss and $\mathrm{SG}_{\infty}$ is solids gain in equilibrium state; $\mathrm{ML}_{t}$ is moisture loss and $\mathrm{SG}_{\mathrm{t}}$ is solids gain after specific dehydration time; $\mathrm{D}_{\mathrm{eM}}$ is moisture diffusivity and $\mathrm{D}_{\mathrm{eS}}$ is solids diffusivity $\left(\mathrm{m}^{2} / \mathrm{s}\right) ; R$ is the radius of a sphere (m); and $t$ is drying time ( $\mathrm{min})$.

The coefficients of effective moisture diffusivity $\mathrm{D}_{\mathrm{eM}}$ and solids diffusivity $\mathrm{D}_{\mathrm{eS}}$ during OD were determined from Eqs. (5) and (6), respectively, by fitting these equations to the experimental data. These series converged with small differences between neighboring points when at least 20 terms were used in the calculations.

\section{Kinetics of Microwave-Vacuum Drying of Whole Cranberries}

Periods characterized by constant and decreasing drying rate (DR) during microwave-vacuum drying of cranberries Eqs. (7) and (8) were determined with the use of the following equations (Henderson and Pabis 1961).

$\mathrm{M}=-\mathrm{k}_{\mathrm{c}} \cdot \mathrm{t}+\mathrm{M}_{1} ; \quad \mathrm{M}_{1} \leq \mathrm{M}<\mathrm{M}_{\mathrm{cr}}$

$\frac{\mathrm{M}}{\mathrm{M}_{\mathrm{cr}}}=\mathrm{e}^{-\mathrm{k}_{\mathrm{f}} \cdot \mathrm{t}} ; \quad \mathrm{M} \geq \mathrm{M}_{\mathrm{cr}}$

where: $M$ is the actual moisture content, $M_{0}$ is the initial moisture content, $M_{1}$ is the moisture content at the beginning of the constant drying rate period, and $M_{\mathrm{cr}}$ is the critical moisture content $\left(\mathrm{kg} \mathrm{H}_{2} \mathrm{O} / \mathrm{kg} \mathrm{DM}\right) ; t$ is drying time (min); and $k_{\mathrm{c}}$ and $k_{\mathrm{f}}$ are the coefficients to be estimated.

It was assumed that microwave-vacuum drying of cranberries would take place in three distinct phases. The initial phase with a steep increase in drying rate (DR) is accompanied by a steep increase in sample temperature. The initial phase is short, and it starts at the beginning of drying at time $t_{0}$ and lasts until time $t_{1}$ when the drying rate ceases to increase. The phase with a constant DR starts at time $t_{1}$ and ends at time $t_{c r}$ when the drying rate decreases. The moisture content $M$ of cranberries at time $t_{c r}$ is equal to $M_{c r}$ and is it referred to as critical moisture content. The final phase with a decreasing DR starts at time $t_{c r}$. Since absolute pressure in the drying chamber was very low $(5 \pm 1 \mathrm{kPa})$ and the intensity of microwave radiation was relatively high $(0.67 \pm 0.01 \mathrm{~W} / \mathrm{g})$, it was assumed that the equilibrium moisture content of cranberries during microwave-vacuum drying was equal to 0 and that a sample subjected to prolonged drying could be completely dry $\left(M_{\infty} \cong\right.$ $0 \mathrm{~kg}$ water $/ \mathrm{kg} \mathrm{DM}$ ). Therefore, equilibrium moisture content was not present in Eq. (8). The duration of each of the three drying phases was determined for each pretreatment conducted under the evaluated drying conditions, and the modeled parameters (7) and (8) and the values of $t_{0}$ and $t_{c r}$ were derived by nonlinear estimation in Statistica 12.5 (StatSoft Inc., Tulsa, USA) software. After differentiation of Eqs. (7) and (8), the drying rates in periods with constant and decreasing DR were derived from Eqs. (9) and (10), respectively.

$\mathrm{DR}=\mathrm{k}_{\mathrm{c}}=$ const $; \quad \mathrm{M}_{1} \leq \mathrm{M}<\mathrm{M}_{\mathrm{cr}}$

$\mathrm{DR}=\mathrm{k}_{\mathrm{f}} \cdot M_{c r} \cdot \mathrm{e}^{-\mathrm{k}_{\mathrm{f}} \cdot \mathrm{t}} ; \quad \mathrm{M} \geq \mathrm{M}_{\mathrm{cr}}$

where DR is the drying rate $(1 / \mathrm{min}) ; \mathrm{k}_{\mathrm{c}}$ is drying rate $(1 / \mathrm{min})$ in the phase with constant DR.

The shrinkage of cranberries was much lower during microwave-vacuum drying than hot-air convectional drying. The above can be attributed to the fact that internal fruit pressure during microwave-vacuum drying is relatively high, which causes the puffing effect and results in low shrinkage. Therefore, the models were developed on the assumption of zero shrinkage. During the microwave-vacuum drying phase with decreasing DR, moisture diffusivity was derived from Eq. (11) (Crank 1975).

$\frac{M}{M_{0}}=\frac{6}{\pi^{2}} \sum_{n=1}^{\infty} \frac{1}{n^{2}} \exp \left(-n^{2} \pi^{2} \frac{D_{e M} t}{R_{S}^{2}}\right)$

where: $M$ is the actual moisture content and $M_{0}$ is the initial moisture content $\left(\mathrm{kg} \mathrm{H}_{2} \mathrm{O} / \mathrm{kg} \mathrm{DM}\right)$; $\mathrm{t}$ is drying time (min); $\mathrm{D}_{\mathrm{eM}}$ is moisture diffusivity $\left(\mathrm{m}^{2} / \mathrm{s}\right) ; R_{\mathrm{S}}$ is the radius of a sphere $(\mathrm{m})$.

Equation (11) describes moisture diffusion in a nonshrinking sphere with radius $\mathrm{R}_{\mathrm{S}}$ dried under constant conditions. 


\section{Extraction Procedure}

Before freeze-drying, cranberries were halved and frozen overnight at $-25^{\circ} \mathrm{C}$ and then dried in the FreeZone 2.5 freeze dryer (Labconco, USA). During FD, pressure was reduced to $16 \mathrm{~Pa}$. The temperature in the drying chamber was $-55^{\circ} \mathrm{C}$, and shelf temperature was $26^{\circ} \mathrm{C}$. Cranberries were kept in the drying chamber for $24 \mathrm{~h}$.

After freeze-drying, phenols were extracted from a pulverized sample (around $0.05 \mathrm{~g}$ ) by sonification for $30 \mathrm{~s}$ (VC 750, Sonics \& Materials, USA) with $1 \mathrm{~mL}$ of acidified $80 \%$ methanol $(0.1 \% \mathrm{HCl}: v / v)$. The mixture was vortexed for $30 \mathrm{~s}$, sonicated repeatedly, vortexed and centrifuged (Centrifuge 5424, Eppendorf, Germany) for $10 \min (13,200 g)$. This step was repeated five times on residues with another $1 \mathrm{~mL}$ of the solvent. The supernatants were collected in a 5-mL flask and kept at $-20{ }^{\circ} \mathrm{C}$ until analysis. The extraction procedure was performed in triplicate.

\section{Total Phenolic Content (TPC)}

Total phenolic content was determined in the Folin-Ciocalteu (FC) assay as described by Shahidi and Naczk (1995) with certain modifications. The sample extract in the amount of $90 \mu \mathrm{L}(2 \mathrm{mg} / \mathrm{mL}), 90 \mu \mathrm{L}$ of the FC reagent (diluted 1:1, $v / v), 180 \mu \mathrm{L}$ of saturated solution of $\mathrm{Na}_{2} \mathrm{CO}_{3}$, and $1440 \mu \mathrm{L}$ of $\mathrm{H}_{2} \mathrm{O}$ were combined and left to react for $25 \mathrm{~min}$ in a thermomixer (Comfort, Eppendorf) at room temperature. Absorbance was measured at $725 \mathrm{~nm}$ in the UV-1800 spectrophotometer (Shimadzu) with a temperature controller (TCC-Controller, Shimadzu). Gallic acid was used as the standard, and the results were based on a standard curve equation of gallic acid $(0.05-0.65 \mathrm{mM})$ and expressed as gallic acid equivalents (GAE) in $\mathrm{mg} / \mathrm{g}$ of DM. The measurements were performed in triplicate.

\section{Total Flavonoid Content (TFC)}

Total flavonoid content was determined based on the method described by Jia et al. (1998) with certain modifications. The extract $(5 \mathrm{mg} / \mathrm{mL})$ in the amount of $1230 \mu \mathrm{L}$ was combined with $62 \mu \mathrm{L}$ of $5 \% \mathrm{NaNO}_{2}$ solution $(\mathrm{m} / \mathrm{v})$. After incubation in a thermomixer (Comfort, Eppendorf) at room temperature for $6 \mathrm{~min}, 123 \mu \mathrm{L}$ of $10 \% \mathrm{AlCl}_{3} \cdot 6 \mathrm{H}_{2} \mathrm{O}$ was added. The mixture was incubated under the same conditions for $6 \mathrm{~min}$, then $410 \mu \mathrm{L}$ of $1 \mathrm{M} \mathrm{NaOH}$ was added, and the mixture was centrifuged for $5 \mathrm{~min}$ at $2800 \mathrm{~g}$ (Centrifuge 5424, Eppendorf). The absorbance of the reaction mixture was measured against a reagent blank at $510 \mathrm{~nm}$ with the UV-1800 spectrophotometer (Shimadzu) with a temperature controller (TCC-Controller, Shimadzu). Catechin was used as the standard, and the results were based on a standard curve equation of catechin (0.016-
$0.5 \mathrm{mM}$ ) and expressed as catechin equivalents (CAE) in $\mathrm{mg} /$ $\mathrm{g}$ DM. The measurements were performed in triplicate.

\section{Total Monomeric Anthocyanins (TMA)}

Total monomeric anthocyanins were determined in accordance with the method proposed by Lee et al. (2005). The extract in the amount of $0.8 \mathrm{~mL}$ was combined with $3.2 \mathrm{~mL}$ of the buffer at $\mathrm{pH} 1(0.025 \mathrm{M} \mathrm{KCl}$ acidified with $\mathrm{HCl})$ or pH 4.5 (0.4 M sodium acetate acidified with glacial acetic acid). The solutions were allowed to stand for $20 \mathrm{~min}$, and absorbance was measured against the appropriate buffer blank at both 520 and $700 \mathrm{~nm}$. Each sample was analyzed in triplicate. Cyanidin-3-glucoside (Cy-3-glu) (MW $449.2 \mathrm{~g} \mathrm{~mol}^{-1}$ ) was used as the standard with molar absorptivity coefficient of $26,900 \mathrm{~mol}^{-1} \mathrm{~cm}^{-1}$. The results were expressed in $\mathrm{mg}$ Cy-3glu/g DM according to the equation proposed by Lee et al. (2005).

\section{Ferric Reducing Antioxidant Power (FRAP)}

The FRAP assay was carried out according to the method described by Benzie and Strain (1999) with certain modifications. Briefly, the FRAP-TPTZ reagent was prepared from sodium acetate buffer ( $300 \mathrm{mM}, \mathrm{pH} 3.6), 10 \mathrm{mM}$ of TPTZ (2,4,6-tripyridylo-S-triazine) solution ( $40 \mathrm{mM} \mathrm{HCl}$ as solvent) and $20 \mathrm{mM}$ of $\mathrm{FeCl}_{3} \cdot 6 \mathrm{H}_{2} \mathrm{O}$ in a volume ratio of 10: 1: 1 respectively. The FRAP reagent was freshly prepared on the day of measurements. An aliquot of $75 \mu \mathrm{l}$ of the extract $(2 \mathrm{mg} /$ $\mathrm{mL}$ ) was combined with $225 \mu \mathrm{l}$ of ultra-pure water and $2250 \mu \mathrm{l}$ of the FRAP reagent (pre-incubated for $5 \mathrm{~min}$ at $25^{\circ} \mathrm{C}$ ). The absorbance of the reagent mixture was measured at $593 \mathrm{~nm}$ after $30 \mathrm{~min}$ incubation at $25^{\circ} \mathrm{C}$. Sample were measured in three replicates. The standard curve was prepared using a Trolox solution $(0.05-0.6 \mathrm{mM})$, and the results were expressed as $\mathrm{mg}$ of Trolox equivalent per $\mathrm{g}$ of dry matter $(\mathrm{mg}$ $\mathrm{TE} / \mathrm{g} \mathrm{DM})$.

\section{Determination of Color Parameters and Indices}

The color parameters of raw and dried cranberries were described with the Miniscan XE Plus spectrophotometer with D 65 standard illuminant, $10^{\circ}$ observer and $8^{\circ}$ diaphragm. The viewed sample area was $5 \mathrm{~mm}$. The display was set to CIE $L^{*} a^{*} b^{*}$ color coordinates, where $L^{*}$ indicates lightness, $a^{*}$ indicates redness $\left(+a^{*}\right)$ or greenness $\left(-a^{*}\right)$, and $b^{*}$ indicates yellowness $\left(+b^{*}\right)$ or blueness $\left(-b^{*}\right)$. The analyzed sample consisted of 35 cranberries. Measurements were performed directly on the surface of cranberries without prior specimen preparation. Total color difference, $\Delta E^{*}$, total saturation difference, $\Delta C^{*}$, and total hue difference, $\Delta H^{*}$ were calculated. Data were analyzed based on the criteria established by the International Commission on Illumination $\left(C I E^{*}\right)$ (Hutchings 
1999) in a procedure described by Zielinska and Markowski (2012). The results were averaged over 35 measurements.

\section{Macroscopic Observations}

Macrographs of cranberry surfaces were acquired with a digital camera (Sony DSC-HX50, Sony Corporation, Tokyo, Japan).

\section{Statistical Analysis}

The differences in color indices between samples were determined by one-way analysis of variance. The significance of differences between samples was determined in Duncan's multiple range test at $p \leq 0.05$. In the remaining samples, differences between groups were determined with the use of the Mann-Whitney U test. The model's goodness of fit to the experimental data was determined based on the values of the coefficient of determination $\left(R^{2}\right)$ and root mean square error (RMSE). Calculations were performed in Statistica 12.5 (StatSoft Inc., Tulsa, USA) software.

\section{Results}

\section{Changes in the Moisture Content and Temperature of Whole Cranberries During Hybrid Dehydration}

The changes in the moisture content and temperature of cranberries subjected to hybrid dehydration are presented in Fig. 1. The hybrid drying process was composed of three sub-processes: (a) pretreatment, (b) osmotic dehydration, and (c) final microwave-vacuum drying. In one experiment, the hybrid drying process consisted only of phases (a) and (c). The duration of the pretreatment phase did not exceed $20 \mathrm{~min}$. The duration of osmotic dehydration was $360 \mathrm{~min}$ in each experiment. During microwave-vacuum drying, fruit temperature initially increased and was then stabilized at a level determined by the applied microwave power density. The process was terminated immediately when a steep increase in temperature was observed. The beginning of this phase marked the complete loss of moisture in the sample. The duration of the microwave-vacuum drying phase ranged from $105.00 \pm 0.08$ to $110.00 \pm 0.08 \mathrm{~min}$. Depending on the applied treatment, the total dehydration time required to produce equilibrium moisture content ranged from $110.00 \pm 0.08$ to $480.00 \pm 0.08 \mathrm{~min}$. Frozen cranberries were subjected to microwave-vacuum drying for $110.00 \pm 0.08 \mathrm{~min}$. During that time, their moisture content was reduced from $9.72 \pm 0.02$ to $0.14 \pm 0.02 \mathrm{~kg}$ $\mathrm{H}_{2} \mathrm{O} / \mathrm{kg}$ DM. Before microwave-vacuum drying, osmotic dehydration was applied to partially dehydrate cranberries and change their sensory and physicochemical properties. Osmotic dehydration decreased the initial moisture content

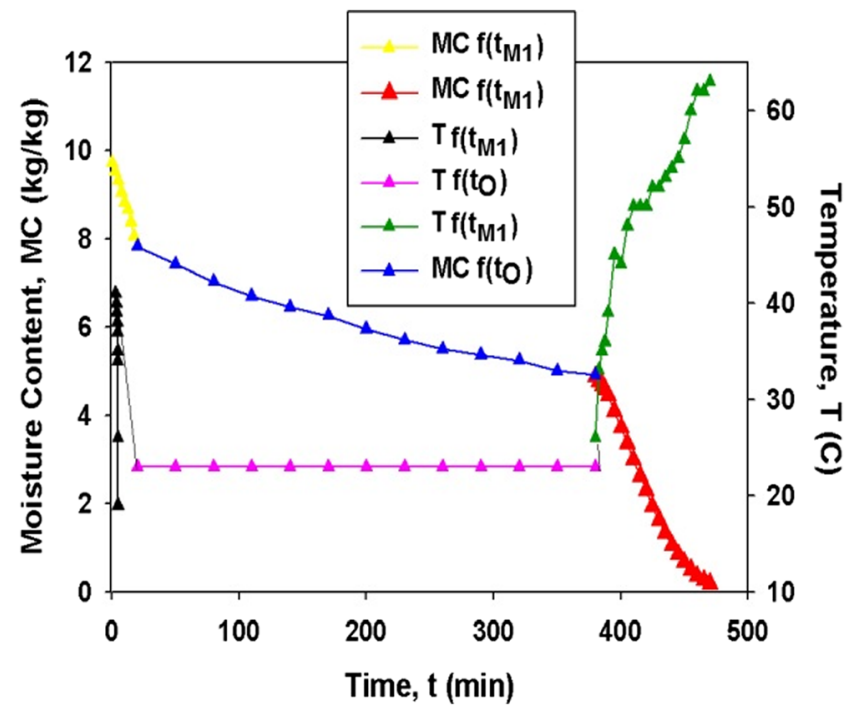

Fig. 1 Exemplary kinetics of hybrid dehydration of cranberry fruits. Oosmotic dehydration; $\mathrm{M}$ - microwave-vacuum

of fruits from $9.72 \pm 0.02$ to $6.60 \pm 0.02 \mathrm{~kg} \mathrm{H}_{2} \mathrm{O} / \mathrm{kg} \mathrm{DM}$ and shortened microwave-vacuum drying time by $23 \%$. Osmotically dehydrated cranberries were microwavevacuum dried for $85.00 \pm 0.08 \mathrm{~min}$. During that time, their moisture content was reduced from $6.60 \pm 0.02$ to $0.10 \pm$ $0.02 \mathrm{~kg} \mathrm{H}_{2} \mathrm{O} / \mathrm{kg} \mathrm{DM}$, which is consistent with the findings of Beaudry et al. (2003, 2004). Microwave-vacuum pretreatment at 100, 500 and $800 \mathrm{~W}$ before osmotic dehydration significantly changed the time of final microwave-vacuum drying. The moisture content of cranberries decreased from 9.72 \pm 0.02 to $4.88 \pm 0.02 \mathrm{~kg} \mathrm{H}_{2} \mathrm{O} / \mathrm{kg} \mathrm{DM}$ during microwavevacuum pretreatment at 100,500 and $800 \mathrm{~W}$, and from 4.71 \pm 0.02 to $3.80 \pm 0.02 \mathrm{~kg} \mathrm{H}_{2} \mathrm{O} / \mathrm{kg}$ DM during osmotic dehydration. The time of final microwave-vacuum drying increased from $80.00 \pm 0.08$ to even $105.00 \pm 0.08 \mathrm{~min}$. Presumably, the presence of sugar on cranberry surfaces sealed the pores and decreased surface permeability during microwave-vacuum drying. The maximum fruit temperature during microwavevacuum pretreatment was $40{ }^{\circ} \mathrm{C}$, and it did not exceed $68^{\circ} \mathrm{C}$ during final microwave-vacuum drying (Fig. 1a-e).

\section{The Effect of Pretreatment on the Kinetics of Osmotic Dehydration of Whole Cranberries}

The effect of microwave-vacuum pretreatment on the kinetics of moisture loss (ML) and solids gain (SG) during osmotic dehydration of cranberries was evaluated, and the results are shown in Fig. 2a, b. At the beginning of the process, the rate of dehydration in $65 \%$ sucrose solution was high due to the difference in osmotic pressure between the solution and cranberries. Subsequently, ML and SG decreased because the concentration gradient between the medium and fruit decreased over dehydration time. The microwave-vacuum pretreatment significantly increased ML and SG. Additionally, the rate of 

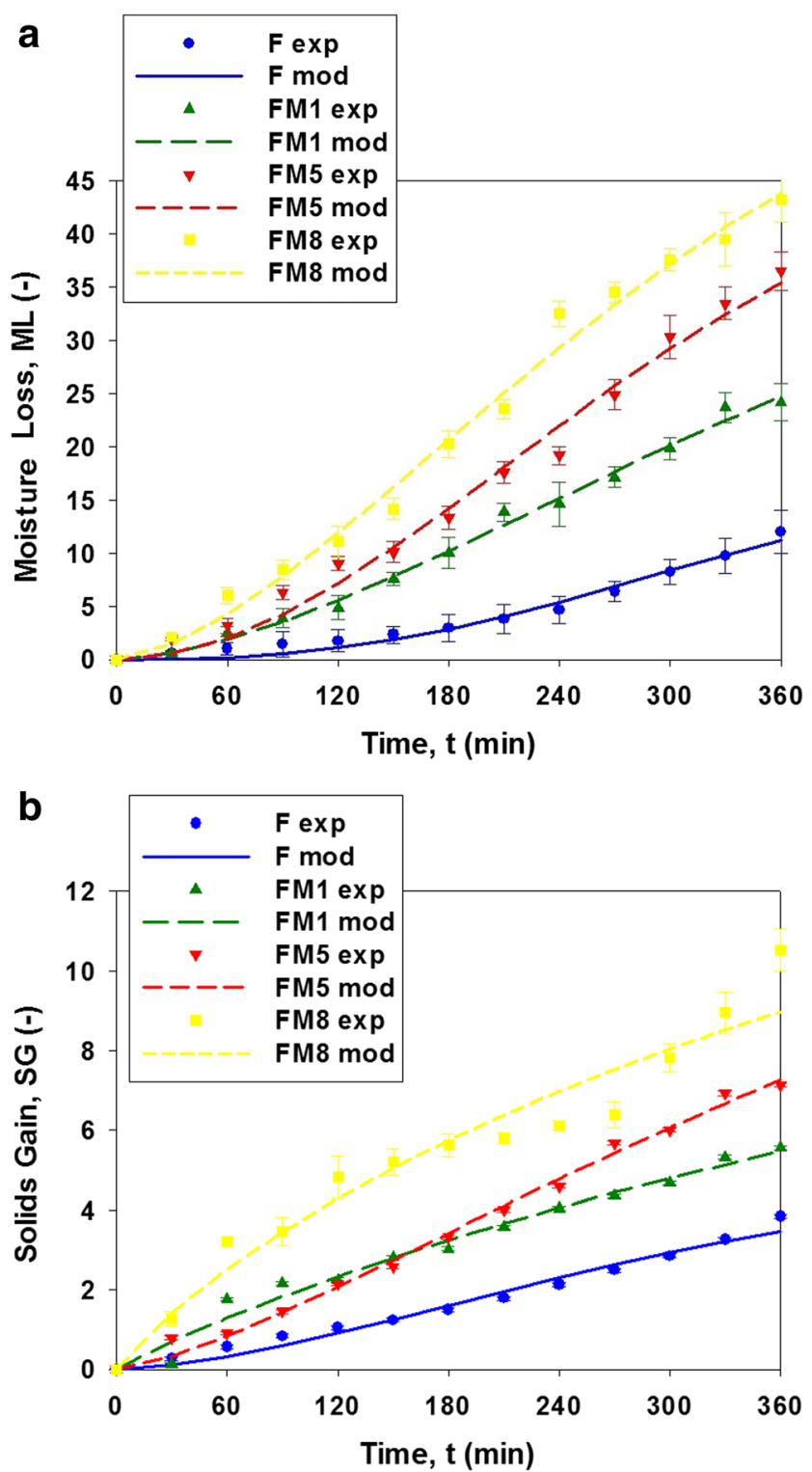

Fig. 2 Effect of initial pretreatment on moisture loss (ML) (a) and solids gain (SG) (b) during osmotic dehydration of whole cranberries. Expexperimental values; mod-values predicted by Weibull's model. Ffrozen cranberries; FM1 - frozen cranberries subjected to microwave vacuum pretreatment at microwave power of $100 \mathrm{~W}$; FM5-frozen cranberries subjected to microwave vacuum pretreatment at microwave power of $500 \mathrm{~W}$; FM8 - frozen cranberries subjected to microwave vacuum pretreatment at microwave power of $800 \mathrm{~W}$

ML and SG increased with microwave power. Untreated cranberries gained solids during osmotic dehydration, and their solids content increased from $9.12 \pm 0.02$ to $13.14 \pm 0.02 \%$. The content of solids increased during osmotic dehydration of cranberries subjected to microwave-vacuum pretreatment at 100,500 and $800 \mathrm{~W}$ from $11.34 \pm 0.02$ to $16.87 \pm 0.02$, $18.62 \pm 0.02$ and $21.85 \pm 0.02 \%$, respectively. The results indicate that microwave-vacuum pretreatment penetrated the moisture barrier of fruit skin.
In the present study, the changes in ML and SG during osmotic dehydration of cranberries were mathematically described using the Weibull model. The identified parameters of the Weibull model for moisture loss (ML) (Eq. 3) and solids gain (SG) (Eq. 4) are shown in Table 2. The values of moisture loss $\left(\mathrm{ML}_{\infty}\right)$ and solids gain $\left(\mathrm{SG}_{\infty}\right)$ in equilibrium state during osmotic dehydration of whole cranberries subjected to different pretreatments are also presented. The calculated values of $\alpha_{\mathrm{M}}$ and $\alpha_{\mathrm{S}}$ were significantly higher for microwave-vacuum pretreated cranberries than for untreated berries, and they increased with microwave power.

The results indicate that the values of $\alpha_{\mathrm{M}}$ are lower than the values of $\alpha_{S}$ for all samples. The above demonstrates that dehydration of cranberries (with or without microwave-vacuum pretreatment) in osmotic solution contributes to impregnation and decreases dehydration. The values of $\mathrm{ML}_{\infty}$ and $\mathrm{SG}_{\infty}$ ranged from $17.2 \pm 1.2$ to $62.8 \pm 2.1$ and from $5.0 \pm 0.4$ to $17.1 \pm 0.7$, respectively. Microwave-vacuum pretreatment significantly increased the values of $\mathrm{ML}_{\infty}$ and $\mathrm{SG}_{\infty}$ in equilibrium state. The values of $\mathrm{ML}_{\infty}$ and $\mathrm{SG}_{\infty}$ increased with a rise in microwave power. The values of $\mathrm{ML}_{\infty}$ and $\mathrm{SG}_{\infty}$ calculated for microwave-vacuum pretreated cranberries were two or even three times higher than those noted in untreated fruit. The values of $R^{2}$ ranged from 0.993 to 0.999 , and the values of RMSE-from 0.17 to $1.33 \%$. High values of $R^{2}$ and low values of RMSE indicate the model fits the data well. The above also indicates that the values predicted by the Weibull model are close to empirical data. In a study by Mancilla et al. (2011), mass transfer during osmotic dehydration of strawberries was modeled with Newton, Henderson-Pabis, Page and Weibull models, and the Weibull model produced the best fit to the experimental data.

Two counter-diffusions took place during osmotic dehydration of whole cranberries, including moisture diffusion from fruit cells into the surrounding sucrose solution and solids diffusion from the solution into biological cells. The effects of initial pretreatment on effective moisture diffusivity $\left(\mathrm{D}_{\mathrm{eM}}\right)$ and solids diffusivity $\left(\mathrm{D}_{\mathrm{eS}}\right)$ during osmotic dehydration of whole cranberries are presented in Table 3. The values of $D_{\mathrm{eM}}$ ranged from $3.0 \pm 0.2 \times 10^{-11}$ to $5.8 \pm 0.2 \times 10^{-11} \mathrm{~m}^{2} / \mathrm{s}$, and the values of $\mathrm{D}_{\mathrm{eS}}$-from $2.1 \pm 0.2 \times 10^{-11}$ to $5.6 \pm 0.2 \times 10^{-11} \mathrm{~m}^{2} / \mathrm{s}$. Similar results were reported by Ochoa-Martínez et al. (2007) for pineapples and apples. In frozen berries, the values of $D_{e M}$ were lower than the values of $D_{e s}$. The reverse was observed in microwave-vacuum pretreated fruit. The above results indicate that osmotic dehydration of frozen fruit contributes to impregnation and decreases dehydration, whereas osmotic dehydration of microwave-vacuum pretreated berries promotes dehydration and decreases impregnation. Presumably, the loss of moisture during rapid 
Table 2 Identified parameters of Weibull's model for moisture loss (ML) (Eq. 3) and solids gain (SG) (Eq. 4), moisture loss $\left(\mathrm{ML}_{\infty}\right)$ and solids gain $\left(\mathrm{SG}_{\infty}\right)$ at equilibrium state during osmotic dehydration of whole cranberries subjected to different initial pretreatments

\begin{tabular}{|c|c|c|c|c|c|c|}
\hline \multirow{3}{*}{ ML Eq. (1) } & Method & $\alpha_{\mathrm{M}}$ & $\beta_{\mathrm{M}}$ & $\mathrm{ML}_{\infty}[\mathrm{g} / 100 \mathrm{~g}$ fresh fruit $]$ & $\operatorname{RMSE}[\%]$ & $R^{2}[-]$ \\
\hline & $\mathrm{F}$ & $0.011 \pm 0.01^{\mathrm{a}}$ & $2.6 \pm 0.1^{\mathrm{a}}$ & $17.2 \pm 1.2^{\mathrm{a}}$ & 0.52 & 0.994 \\
\hline & FM1 & $0.043 \pm 0.04^{\mathrm{b}}$ & $1.6 \pm 0.1^{\mathrm{b}}$ & $44.3 \pm 1.7^{\mathrm{b}}$ & 0.61 & 0.999 \\
\hline \multirow{7}{*}{ SG Eq. (2) } & FM5 & $0.042 \pm 0.03^{\mathrm{b}}$ & $1.9 \pm 0.1^{\mathrm{bc}}$ & $48.3 \pm 1.4^{\mathrm{b}}$ & 1.31 & 0.996 \\
\hline & FM8 & $0.070 \pm 0.11^{\mathrm{c}}$ & $1.6 \pm 0.2^{\mathrm{b}}$ & $62.8 \pm 2.1^{\mathrm{c}}$ & 1.33 & 0.997 \\
\hline & Method & $\alpha_{\mathrm{S}}$ & $\beta_{\mathrm{S}}$ & $\mathrm{SG}_{\infty}[\mathrm{g} / 100 \mathrm{~g}$ fresh fruit $]$ & RMSE [\%] & $R^{2}[-]$ \\
\hline & $\mathrm{F}$ & $0.067 \pm 0.07^{\mathrm{a}}$ & $1.6 \pm 0.2^{\mathrm{a}}$ & $5.0 \pm 0.4^{\mathrm{a}}$ & 0.17 & 0.993 \\
\hline & FM1 & $0.097 \pm 0.12^{\mathrm{b}}$ & $0.9 \pm 0.1^{\mathrm{c}}$ & $13.9 \pm 0.6^{\mathrm{b}}$ & 0.24 & 0.996 \\
\hline & FM5 & $0.092 \pm 0.02^{\mathrm{b}}$ & $1.4 \pm 0.1^{\mathrm{b}}$ & $13.9 \pm 0.7^{\mathrm{b}}$ & 0.18 & 0.999 \\
\hline & FM8 & $0.159 \pm 0.14^{\mathrm{c}}$ & $0.9 \pm 0.2^{\mathrm{d}}$ & $17.1 \pm 0.7^{\mathrm{c}}$ & 0.65 & 0.985 \\
\hline
\end{tabular}

Table shows the mean values \pm standard errors

Same letters in the same column mean that the mean values are not significantly different at a confidence level of $95 \%(p \leq 0.05)$

F-frozen cranberries; FM1 - frozen cranberries subjected to microwave vacuum pretreatment at microwave power of $100 \mathrm{~W}$; FM5 - frozen cranberries subjected to microwave vacuum pretreatment at microwave power of $500 \mathrm{~W}$; FM8 - frozen cranberries subjected to microwave vacuum pretreatment at microwave power of $800 \mathrm{~W}$ microwave-vacuum pretreatment induced high stress and produced surface microcracks that improved moisture transfer. The values of $\mathrm{D}_{\mathrm{eM}}$ increased with a rise in microwave power (Table 3 ). The values of $R^{2}$ ranged from 0.767 to 0.943 , and the values of RMSE-from 0.61 to $6.81 \%$. The model did not fit the data well. However, a theoretical model based on Fick's second law of diffusion is often used to estimate the order of magnitude of the diffusion coefficient (Andrade et al. 2007; Souraki et al. 2012).

Table 3 Effect of initial pretreatment on the values of effective moisture $\left(D_{\mathrm{eM}}\right)$ and solids diffusivities $\left(\mathrm{D}_{\mathrm{eS}}\right)$ during osmotic dehydration of whole cranberries

\begin{tabular}{lllll}
\hline & Method & $\mathrm{D}_{\mathrm{eM}} \times 10^{11}\left[\mathrm{~m}^{2} / \mathrm{s}\right]$ & RMSE [\%] & $R^{2}[-]$ \\
MR Eq. (5) & F & $3.0 \pm 0.2^{\mathrm{a}}$ & 6.72 & 0.767 \\
& FM1 & $3.0 \pm 0.3^{\mathrm{a}}$ & 3.51 & 0.846 \\
& FM5 & $5.6 \pm 0.2^{\mathrm{b}}$ & 6.81 & 0.829 \\
& FM8 & $5.8 \pm 0.2^{\mathrm{b}}$ & 4.96 & 0.863 \\
& & & & \\
SR Eq. (6) & Fethod & $\mathrm{D}_{\mathrm{eS}} \times 10^{11}\left[\mathrm{~m}^{2} / \mathrm{s}\right]$ & RMSE [\%] & $R^{2}[-]$ \\
& FM1 & $5.6 \pm 0.2^{\mathrm{a}}$ & 4.73 & 0.906 \\
& FM5 & $3.1 \pm 0.2^{\mathrm{d}}$ & 0.61 & 0.943 \\
& FM8 & $4.5 \pm 0.4^{\mathrm{c}}$ & 2.25 & 0.882 \\
& & 1.15 & 0.939 \\
\hline
\end{tabular}

Table shows the mean values \pm standard errors

Same letters in the same column mean that the mean values are not significantly different at a confidence level of $95 \%(p \leq 0.05)$

$\mathrm{MR}$ - moisture loss ratio; SR — solids gain ratio

F-frozen cranberries; FM1 - frozen cranberries subjected to microwave vacuum pretreatment at microwave power of $100 \mathrm{~W}$; FM5 - frozen cranberries subjected to microwave vacuum pretreatment at microwave power of $500 \mathrm{~W}$; FM8 - frozen cranberries subjected to microwave vacuum pretreatment at microwave power of $800 \mathrm{~W}$

\section{The Effect of Initial Pretreatment on the Kinetics of Microwave-Vacuum Drying of Whole Cranberries}

The influence of initial pretreatment on the kinetics of microwave-vacuum drying of cranberries subjected to different pretreatments and drying treatments was evaluated, and the results are shown in Fig. 3 and Table 4. The changes in the drying rates and temperatures of differently pretreated cranberries that were microwave dried under reduced pressure are presented in Fig. 3. Generally, mass transfer during dehydration of wet solids is controlled by external or internal resistance (Karel and Lund 2003; Rizvi 2005). If external resistance to mass transfer is the predominant force, the drying rate is constant. Otherwise, the drying rate decreases. Figure 3 shows that regardless of the type of pretreatment, microwave-vacuum drying of cranberries can be characterized by a relatively long phase with a constant drying rate, followed by a relatively short phase with a decreasing drying rate. The above indicates microwave-vacuum drying of whole cranberries features a long drying period during which moisture is removed from the surface and internal moisture transfer caused by the pressure gradient inside fruit is sufficient to maintain a constant rate of mass transfer at the surface. There is only a relatively short period during which the surface of fruit is not saturated, and the rate of moisture transfer from the interior to the surface is lower than the rate of evaporation from the surface. The average drying rates during the period with a constant drying rate and the initial and final moisture content of cranberries during that period are presented in Table 4. Many researchers investigating the kinetics of microwave-vacuum drying of fruit, vegetables and mushrooms have reported only the long phase with a decreasing drying rate, accompanied by a very short 

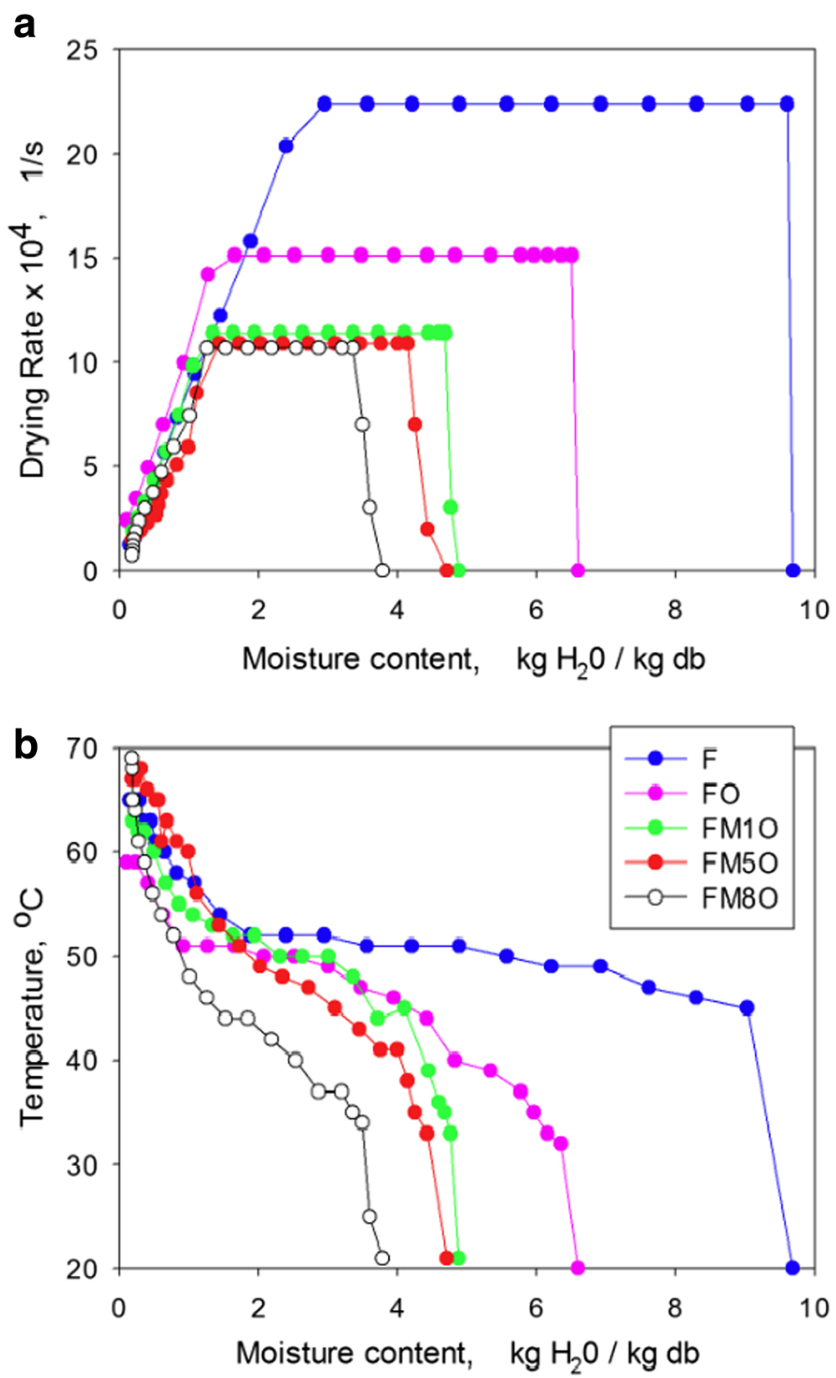

Fig. 3 Effect of initial pretreatment on drying rates (a) and material temperature (b) changes during microwave vacuum drying of whole cranberries. F-frozen cranberries; $\mathrm{FO}$ - frozen cranberries subjected to osmotic dehydration; FM1O - frozen cranberries subjected to microwave vacuum pretreatment at microwave power of $100 \mathrm{~W}$ followed by osmotic dehydration; FM5O - frozen cranberries subjected to microwave vacuum pretreatment at microwave power of $500 \mathrm{~W}$ followed by osmotic dehydration; FM8O - frozen cranberries subjected to microwave vacuum pretreatment at microwave power of $800 \mathrm{~W}$ followed by osmotic dehydration

phase or the absence of a phase with a constant drying rate (Zielinska and Michalska 2016; Béttega et al. 2014; Dak and Pareek 2014; Giri and Prasad 2007). In contrast, Bondaruk et al. (2007) reported a relatively long phase with a constant drying rate during microwave-vacuum drying of potatoes, which is consistent with our results.

In the present study, during microwave-vacuum drying of pretreated frozen cranberries, the drying rate increased steeply to $2.260 \pm 0.010 \times 10^{-3} 1 / \mathrm{s}$, after which it remained constant until the moisture content of cranberries decreased from 9.72 \pm 0.02 to $2.41 \pm 0.02 \mathrm{~kg} \mathrm{H}_{2} \mathrm{O} / \mathrm{kg} \mathrm{DM}$. The phase with a constant drying rate was followed by a phase with a decreasing drying rate. A similar pattern was observed in all samples. The analyzed samples differed only in DR during the period with a constant drying rate, which was determined at $1.491 \pm$ $0.006 \times 10^{-3} 1 / \mathrm{s}$ in samples subjected to osmo-microwavevacuum drying and $1.117 \pm 0.008 \times 10^{-3} 1 / \mathrm{s}$ in samples subjected to microwave-vacuum pretreatment and osmomicrowave-vacuum drying.

The results also indicate that the type of pretreatment influenced the DR of cranberries during the period with a constant DR. Presumably, the presence of a distinct phase with a constant drying rate in cranberries can be attributed to rapid moisture evaporation from berries, accompanied by a high and probably initially constant pressure gradient inside microwave-vacuum dried berries. The microstructure of berries is determined by the type of applied pretreatment, and it can influence the forces inside fruit.

The changes in the moisture content of cranberries during microwave-vacuum drying were accompanied by changes in fruit temperature. Generally, the temperature of dried cranberries continued to increase in all samples. However, the rate of that increase was significantly lower during the phase with a constant drying rate than the phase with a decreasing drying rate (Fig. 3b). A lower rise in temperature during the phase with a constant DR than during the phase with a decreasing DR can be explained by the fact that the thermal energy generated inside samples during the period with a constant DR, when the moisture content of fruit is high, is used mainly to evaporate water and only a small amount of that energy is accumulated. On the other hand, during the period with a decreasing DR when the moisture content of fruit is relatively low, most of the heat generated inside the sample is accumulated; therefore, fruit temperature increases rapidly because only a small amount of the supplied heat is used for moisture evaporation.

The influence of pretreatment on moisture diffusivity $\left(D_{\mathrm{eM}}\right)$ in cranberries during microwave-vacuum drying with a decreasing DR is presented in Table 5. The values of $\mathrm{D}_{\mathrm{eM}}$ ranged from $0.923 \pm 0.133 \times 10^{-9}$ to $2.371 \pm 0.489 \times 10^{-9} \mathrm{~m}^{2} / \mathrm{s}$. The highest values of $\mathrm{D}_{\mathrm{eM}}$ were observed in osmotically dehydrated samples without microwave-vacuum pretreatment, whereas the lowest values were noted in samples subjected to microwavevacuum pretreatment. The above can be attributed to the fact that solids gain during osmotic dehydration was higher in microwave-pretreated samples than in berries that had not been pretreated, which produced a sugarimpregnated microstructure in berries and increased the internal resistance of moisture diffusion. Microwavevacuum pretreatment conducted at higher microwave power significantly lowered the values of $D_{e M}$ (Table 5). The values of $\mathrm{R}^{2}$ and RMSE ranged from 0.887 to 0.956 and from 4.11 to $12.29 \%$, respectively. The results clearly indicate that the pressure inside 
Table 4 Effect of initial pretreatment on the values of model (7) and (8) parameters

\begin{tabular}{|c|c|c|c|c|c|c|c|c|}
\hline \multirow[b]{2}{*}{ Method } & \multicolumn{4}{|c|}{ Constant drying rate period, Eq. (7) } & \multicolumn{4}{|c|}{ Falling drying rate period, Eq. (8) } \\
\hline & $\mathrm{M}_{1}\left[\mathrm{~kg} \mathrm{H} \mathrm{H}_{2} \mathrm{O} / \mathrm{kg} \mathrm{DM}\right]$ & $\mathrm{k}_{\mathrm{c}} \times 10^{3}[1 / \mathrm{s}]$ & RMSE [\%] & $\mathrm{R}[-]$ & $\mathrm{M}_{\mathrm{cr}}\left[\mathrm{kg} \mathrm{H} \mathrm{k}_{2} \mathrm{O} / \mathrm{kg} \mathrm{DM}\right]$ & $\mathrm{k}_{\mathrm{f}} \times 10^{3}[1 / \mathrm{s}]$ & RMSE [\%] & $R^{2}[-]$ \\
\hline $\mathrm{F}$ & $9.72 \pm 0.02^{\mathrm{a}}$ & $2.260 \pm 0.010^{\mathrm{a}}$ & 5.90 & 0.999 & $2.41 \pm 0.02^{\mathrm{a}}$ & $8.52 \pm 0.01^{\mathrm{a}}$ & 2.93 & 0.998 \\
\hline FO & $6.60 \pm 0.02^{\mathrm{b}}$ & $1.491 \pm 0.006^{\mathrm{b}}$ & 3.52 & 0.999 & $1.67 \pm 0.02^{\mathrm{b}}$ & $1.14 \pm 0.07^{\mathrm{b}}$ & 7.52 & 0.982 \\
\hline FM1O & $4.88 \pm 0.02^{\mathrm{c}}$ & $1.117 \pm 0.008^{\mathrm{d}}$ & 4.34 & 0.999 & $1.07 \pm 0.02^{\mathrm{d}}$ & $0.88 \pm 0.03^{\mathrm{c}}$ & 2.89 & 0.991 \\
\hline FM5O & $4.71 \pm 0.02^{\mathrm{d}}$ & $1.148 \pm 0.009^{\mathrm{c}}$ & 4.31 & 0.999 & $1.10 \pm 0.02^{\mathrm{c}}$ & $0.51 \pm 0.02^{\mathrm{e}}$ & 3.88 & 0.973 \\
\hline FM8O & $3.80 \pm 0.02^{\mathrm{e}}$ & $1.050 \pm 0.007^{\mathrm{e}}$ & 3.61 & 0.999 & $1.01 \pm 0.02^{\mathrm{e}}$ & $0.79 \pm 0.03^{\mathrm{d}}$ & 3.35 & 0.968 \\
\hline
\end{tabular}

Table show the mean values \pm standard errors

Same letters in the same column mean that the mean values are not significantly different at a confidence level of $95 \%(p \leq 0.05)$

$\mathrm{F}$ - frozen cranberries; FO - frozen cranberries subjected to osmotic dehydration; FM1O - frozen cranberries subjected to microwave vacuum pretreatment at microwave power of $100 \mathrm{~W}$ followed by osmotic dehydration; FM5O - frozen cranberries subjected to microwave vacuum pretreatment at microwave power of $500 \mathrm{~W}$ followed by osmotic dehydration; FM8O - frozen cranberries subjected to microwave vacuum pretreatment at microwave power of $800 \mathrm{~W}$ followed by osmotic dehydration

cranberries during microwave-vacuum drying is proportional to DR. The data presented in Fig. 3 clearly demonstrate that DR at the beginning of the period with a decreasing DR was lower in microwave-pretreated samples than in samples that had not been pretreated. The above indicates that the pressure inside pretreated cranberries was lower than in non-pretreated samples. The pressure gradient inside a sample influences drying, and speeds up the movement of water vapor from dried fruit. In consequence, effective moisture diffusivity increased with a rise in pressure inside berries, which explains the differences in effective moisture diffusivity between samples.

Table 5 Effect of initial pretreatment on the values of effective moisture diffusivity $\left(\mathrm{D}_{\mathrm{eM}}\right)$ of whole cranberries during microwave-vacuum drying (MWVD)

\begin{tabular}{lllll}
\hline Method & $\mathrm{M}_{1}\left[\mathrm{~kg} \mathrm{H} \mathrm{H}_{2} \mathrm{O} / \mathrm{kg} \mathrm{DM}\right]$ & $\mathrm{D}_{\mathrm{eM}} \times 10^{9}\left[\mathrm{~m}^{2} / \mathrm{s}\right]$ & $\mathrm{RMSE}[\%]$ & $R^{2}[-]$ \\
\hline $\mathrm{F}$ & $2.41 \pm 0.02^{\mathrm{a}}$ & $1.86 \pm 0.18^{\mathrm{b}}$ & 11.09 & 0.947 \\
$\mathrm{FO}$ & $1.67 \pm 0.02^{\mathrm{b}}$ & $2.37 \pm 0.49^{\mathrm{a}}$ & 12.29 & 0.906 \\
$\mathrm{FM} 10$ & $1.07 \pm 0.02^{\mathrm{d}}$ & $1.63 \pm 0.31^{\mathrm{c}}$ & 10.59 & 0.892 \\
FM5O & $1.10 \pm 0.02^{\mathrm{c}}$ & $0.92 \pm 0.13^{\mathrm{d}}$ & 8.29 & 0.887 \\
FM8O & $1.01 \pm 0.02^{\mathrm{e}}$ & $1.63 \pm 0.14^{\mathrm{c}}$ & 4.11 & 0.956 \\
\hline
\end{tabular}

Table shows the mean values \pm standard errors

Same letters in the same column mean that the mean values are not significantly different at a confidence level of $95 \%(p \leq 0.05)$

F-frozen cranberries; FO - frozen cranberries subjected to osmotic dehydration; FM1O - frozen cranberries subjected to microwave vacuum pretreatment at microwave power of $100 \mathrm{~W}$ followed by osmotic dehydration; FM5O - frozen cranberries subjected to microwave vacuum pretreatment at microwave power of $500 \mathrm{~W}$ followed by osmotic dehydration; FM8O - frozen cranberries subjected to microwave vacuum pretreatment at microwave power of $800 \mathrm{~W}$ followed by osmotic dehydration

\section{Total Phenolic Content, Total Content of Monomeric Anthocyanins, Total Flavonoid Content and Ferric Reducing Antioxidant Power of Cranberries}

The effect of initial pretreatment and microwave-vacuum drying on total phenolic content (TPC), total content of monomeric anthocyanins (TMA), total flavonoid content (TFC) and ferric reducing antioxidant power (FRAP) of cranberries was evaluated. The results are shown in Table 6.

Different pretreatments and dehydration processes caused significant changes in TPC, TFC and TMA values of cranberries. The total content of phenolic compounds in freezedried cranberries was determined at $22.5 \pm 0.2 \mathrm{mg} \mathrm{GAE} / \mathrm{g} \mathrm{DM}$ (Table 6). Microwave-vacuum dried (FM1) and osmomicrowave-vacuum dried (FOM1) frozen berries were characterized by a higher content of phenolic compounds than freeze-dried samples. Furthermore, microwave-vacuum pretreatment at low microwave power before dehydration (FM1OM1) also produced cranberries with a high content of polyphenols (23.9 $\pm 0.9 \mathrm{mg} \mathrm{GAE} / \mathrm{g} \mathrm{DM})$ (Table 6). After dehydration under the above conditions, the content of polyphenols was similar to that of freeze-dried berries. However, the increase in microwave power from $100 \mathrm{~W}$ to $500 \mathrm{~W}$ and $800 \mathrm{~W}$ produced lower TPC values. The polyphenol content of cranberries dried by FM5OM1 and FM8OM1 was $28 \%$ and $22 \%$ lower, respectively, in comparison with control (FD) (Table 6).

Cranberries subjected to different pretreatments and dehydration processes also differed in TMA values. After dehydration, the content of total monomeric anthocyanins was similar to that of the freeze-dried sample, but only in cranberries that had been subjected to microwave-vacuum pretreatment at low microwave power of $100 \mathrm{~W}$ before dehydration $(4.08 \mathrm{mg} \mathrm{Cy}$ 3G/g DM and $3.85 \mathrm{mg}$ Cy-3G/g DM, respectively). The content of anthocyanins $(2.1 \pm 0.1 \mathrm{mg} \mathrm{Cy}-3 \mathrm{G} / \mathrm{g} \mathrm{DM}$ and $2.2 \pm$ 
Table 6 Effect of initial pretreatment on total phenolic content (TPC), total monomeric anthocyanins (TMA), total flavonoid content (TFC), ferric reducing antioxidant power (FRAP) of cranberries subjected to different initial pretreatments

\begin{tabular}{lllll}
\hline Method & $\begin{array}{l}\text { TPC } \\
{[\mathrm{mg} \mathrm{GAE} / \mathrm{g} \mathrm{DM}]}\end{array}$ & $\begin{array}{l}\text { TMA } \\
{[\mathrm{mg} \mathrm{Cy}-3 \mathrm{G} / \mathrm{g} \mathrm{DM}]}\end{array}$ & $\begin{array}{l}\text { TFC } \\
{[\mathrm{mg} \text { CAE/g DM }]}\end{array}$ & $\begin{array}{l}\text { FRAP } \\
{[\mathrm{mg} \text { TE/g DM }]}\end{array}$ \\
\hline F & $22.5 \pm 0.2^{\mathrm{c}}$ & $4.1 \pm 0.2^{\mathrm{b}}$ & $3.0 \pm 0.1^{\mathrm{c}}$ & $39.0 \pm 1.3^{\mathrm{c}}$ \\
FM1 & $32.4 \pm 0.4^{\mathrm{a}}$ & $6.0 \pm 0.2^{\mathrm{a}}$ & $3.9 \pm 0.1^{\mathrm{a}}$ & $56.3 \pm 2.0^{\mathrm{a}}$ \\
FOM1 & $31.6 \pm 0.8^{\mathrm{a}}$ & $6.1 \pm 0.2^{\mathrm{a}}$ & $4.0 \pm 0.3^{\mathrm{a}}$ & $56.5 \pm 1.6^{\mathrm{a}}$ \\
FM1OM1 & $23.9 \pm 0.9^{\mathrm{b}}$ & $3.9 \pm 0.2^{\mathrm{b}}$ & $3.4 \pm 0.1^{\mathrm{b}}$ & $44.6 \pm 1.2^{\mathrm{b}}$ \\
FM5OM1 & $16.2 \pm 0.3^{\mathrm{e}}$ & $2.1 \pm 0.1^{\mathrm{c}}$ & $2.3 \pm 0.1^{\mathrm{d}}$ & $27.2 \pm 0.7^{\mathrm{e}}$ \\
FM8OM1 & $17.5 \pm 0.6^{\mathrm{d}}$ & $2.2 \pm 0.1^{\mathrm{c}}$ & $2.4 \pm 0.1^{\mathrm{d}}$ & $29.1 \pm 0.6^{\mathrm{d}}$ \\
\hline
\end{tabular}

Table show the mean values \pm standard errors

Same letters in the same column mean that the mean values are not significantly different at a confidence level of $95 \%(p \leq 0.05)$

F-frozen cranberries subjected to freeze drying; FM1 - frozen cranberries subjected to microwave vacuum drying at microwave power of $100 \mathrm{~W}$; FOM1 - frozen cranberries subjected to osmotic dehydration and microwave vacuum drying at microwave power of $100 \mathrm{~W}$; FM1OM1 - frozen cranberries subjected to microwave vacuum pretreatment at microwave power of $100 \mathrm{~W}$ followed by osmotic dehydration and microwave vacuum drying at microwave power of $100 \mathrm{~W}$; FM5OM1 - frozen cranberries subjected to microwave vacuum pretreatment at microwave power of $500 \mathrm{~W}$ followed by osmotic dehydration and microwave vacuum drying at microwave power of $100 \mathrm{~W}$; FM8OM1 - frozen cranberries subjected to microwave vacuum pretreatment at microwave power of $800 \mathrm{~W}$ followed by osmotic dehydration and microwave vacuum drying at microwave power of $100 \mathrm{~W}$
$0.1 \mathrm{mg}$ Cy-3G/g DM) was considerably lower in samples subjected to microwave-vacuum pretreatment at higher microwave power of $500 \mathrm{~W}$ (FM5OM1) and $800 \mathrm{~W}$ (FM8OM1). In contrast, the content of TMA in cranberries subjected to microwave-vacuum (FM1) and osmo-microwave-vacuum (FOM1) drying was around 1.5 times higher than in freezedried samples (FD) (Table 6).

The analyzed pretreatments and drying techniques exerted a similar influence on TFC values as on the values of TPC and TMA. However, the values of TFC were less differentiated and ranged from $2.3 \pm 0.1 \mathrm{mg} \mathrm{CAE} / \mathrm{g} \mathrm{DM}$ to $4.0 \pm 0.3 \mathrm{mg}$ $\mathrm{CAE} / \mathrm{g}$ DM. Total flavonoid content was also higher in berries processed by FM1, FOM1 and FM1OM1 than in the freezedried sample, and it was lower in cranberries subjected to microwave-vacuum pretreatment at higher microwave power (FM8OM1 and FM5OM1) (Table 6).

Similar values of TPC, TMA and TFC in freeze-dried cranberries were also observed by other authors. However, it should be noted that the total polyphenol content of cranberries is also determined by cultivar (Borowska et al. 2009; Brown et al. 2012; Leusink et al. 2010).

The presented results indicate that FM1 and FOM1 are more effective in preserving the high polyphenol content of berries than microwave-vacuum pretreatment. However, it should be noted that microwave-vacuum drying at low power $(100 \mathrm{~W})$ also led to high retention of polyphenols in cranberries. Cranberries subjected to microwave-vacuum drying at higher power $(500 \mathrm{~W}$ and $800 \mathrm{~W})$ were characterized by the lowest polyphenol content which was $70 \%$ lower than in freeze-dried cranberries (Table 6). The above could be attributed to several factors. Dehydration damages fruit cells and leads to skin breakage. Structural changes inside cells are irreversible and can provoke the release of bound compounds from the matrix to increase their availability. These processes are responsible for the higher diffusion of compounds, in particular polyphenols, from the skin to the pulp (Marquez et al. 2014). Anthocyanins are the main polyphenols in cranberry skin, therefore, drying should increase the concentration of red compounds in the pulp and prevent the formation of brown compounds. When fruits are dried at a constant and high temperature (minimum $40{ }^{\circ} \mathrm{C}$ ), water evaporation is a continuous process that decreases the diffusion of molecular oxygen to berries, which is a prerequisite for browning reactions (Marquez et al. 2014). It should also be noted that the stability of anthocyanins is influenced by other factors, including chemical structure, $\mathrm{pH}$, enzymes, oxygen, light, and the presence of ascorbic acid, sugars, metals and copigments. Researchers who investigated the degradation rates of anthocyanins concluded that this parameter is time- and temperature-dependent and that anthocyanins are particularly sensitive to temperatures above $70{ }^{\circ} \mathrm{C}$ (Sarkis et al. 2013; Jiminez et al. 2010; Sadilova et al. 2006). Cell wall damage could also trigger the release of enzymes (polyphenol oxidase and peroxidase) and decrease the content of phenolic compounds in cranberries, but drying temperatures during FM1, FOM1 and FM1OM1 $\left(\sim 68^{\circ} \mathrm{C}\right)$ would deactivate those enzymes, prevent the loss of phenolic compounds and, consequently, increase the values of TPC, TMA and TFC (Table 6).

The significant decrease in the polyphenol content of cranberries subjected to microwave-vacuum drying at higher microwave power $(500 \mathrm{~W}$ and $800 \mathrm{~W})$ could also be related to more pronounced structural changes under the above drying conditions. Greater shrinkage and surface microcracking was observed in cranberries subjected to microwave-vacuum 
treatment at higher microwave power. The resulting loss of polyphenols, which was higher than in untreated cranberries or in cranberries subjected to low power microwave treatment, could be attributed a higher number of surface fissures and cracks in fruit processed at higher microwave power (Figs. 4 and 5). Thus, the relatively lower values of TPC, TMA and TFC in cranberries that were microwave-vacuum dried at microwave power of $500 \mathrm{~W}$ and $800 \mathrm{~W}$ resulted mainly from the loss of polyphenols (Table 6). Similar results were reported by Zielinska and Michalska (2016) in dried blueberries. Wojdylo et al. (2009) observed that strawberries dried at higher power (MW $480 \mathrm{~W}$ ) were characterized by a lower content of anthocyanins and other polyphenols than samples dried at lower power (MW $360 \mathrm{~W}$ and MW $240 \mathrm{~W}$ ). These results suggest that the length and intensity of heat treatment are directly correlated with the magnitude of anthocyanin loss. Similar results were reported by Kwok et al. (2004). Wray and Ramaswamy (2015) also noted that the quality of microwave-osmotic/microwave-vacuum dried cranberries was comparable to that of cranberries that were freeze dried over a much shorter period of time. Freeze-dried cranberries were also characterized by much higher quality in terms of color, anthocyanin content and cellular structures than cranberries subjected to vacuum or convective air drying. According to van der Sluis et al. (2005), anthocyanins glycosylated with arabinose sugars are relatively more susceptible to oxidation during air drying than anthocyanins glycosylated with other sugars. However, the loss of anthocyanins induced by heat and oxidation is substantially lower during microwavevacuum drying and freeze drying than during air drying (Mejia-Meza et al. 2008). Leusink et al. (2010) also found that cranberries subjected to microwave-vacuum drying and freeze drying were characterized by higher quality and were more appealing to health-conscious consumers.

The influence of pretreatment and drying technique on the antioxidant potential of cranberries evaluated in the FRAP assay is presented in Table 6. These results indicate that microwave-vacuum pretreatment at higher microware power (FM8OM1 and FM5OM1) before hybrid dehydration decreased the content of compounds with ferric (III) reducing ability (Table 6). In cranberries microwaved at $800 \mathrm{~W}$, FRAP values were approximately $75 \%$ lower than those noted in the freeze-dried sample. Significantly higher values were obtained in cranberries subjected to microwave-vacuum treatment at lower microwave power (FM1OM1). In addition, the FRAP values of cranberries subjected to FM1 and FOM1 treatments were twice higher than in FM8OM1 and FM5OM1 treatments. Wojdylo et al. (2014) demonstrated that regardless a
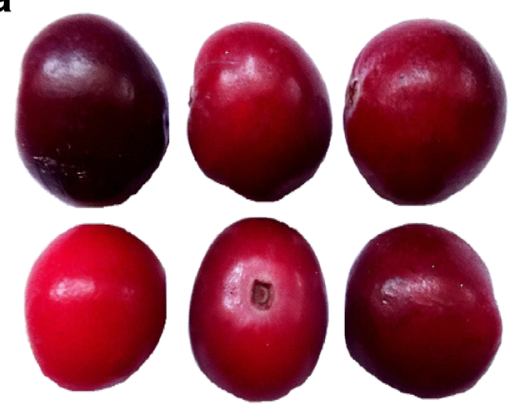

b
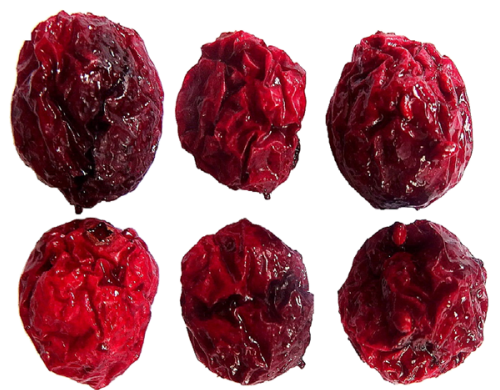

d
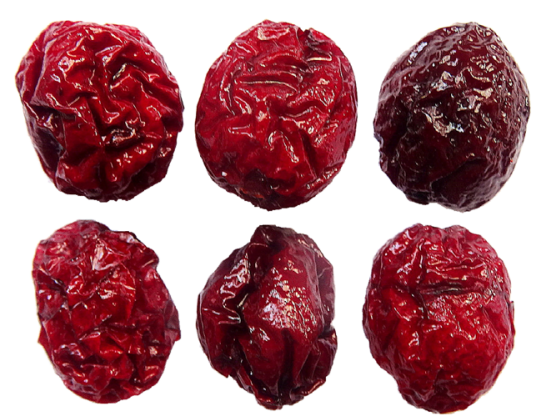

d
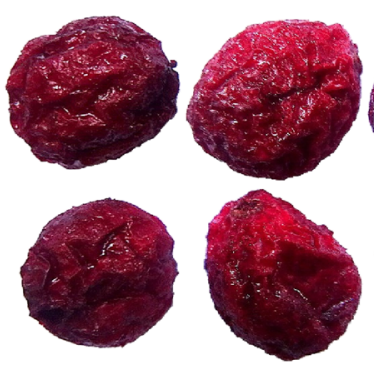

e
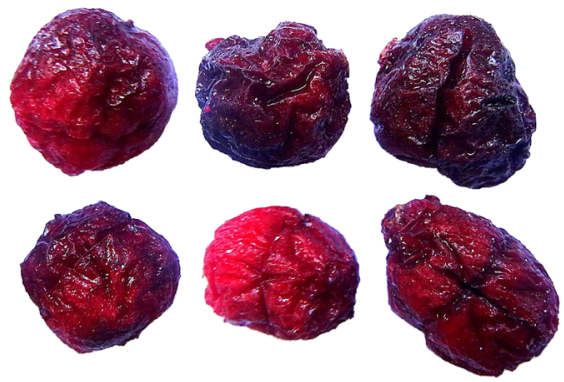

f
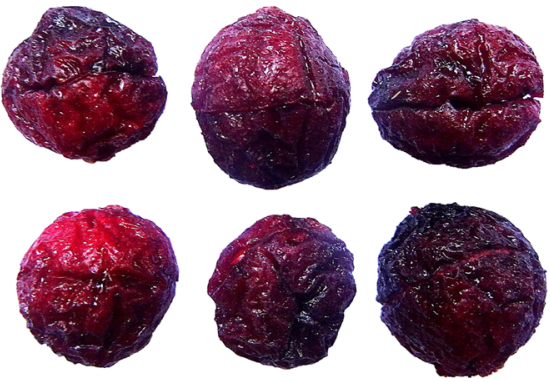

Fig. 4 Overall appearance of cranberries subjected to different initial pretreatment and microwave-vacuum drying: (a) F; (b) FM1; (c) FOM1; (d) FM1OM1; (e) FM5OM1; (f) FM8OM1. F-frozen cranberries; FM1 - frozen cranberries subjected to microwave vacuum drying at microwave power of $100 \mathrm{~W}$; FOM1 - frozen cranberries subjected to osmotic dehydration and microwave vacuum drying at microwave power of $100 \mathrm{~W}$; FM1OM1 - frozen cranberries subjected to microwave vacuum pretreatment at microwave power of $100 \mathrm{~W}$ followed by osmotic dehydration and microwave vacuum drying at microwave power of $100 \mathrm{~W}$; FM5OM1 - frozen cranberries subjected to microwave vacuum pretreatment at microwave power of $500 \mathrm{~W}$ followed by osmotic dehydration and microwave vacuum drying at microwave power of $100 \mathrm{~W}$; FM8OM1 - frozen cranberries subjected to microwave vacuum pretreatment at microwave power of $800 \mathrm{~W}$ followed by osmotic dehydration and microwave vacuum drying at microwave power of $100 \mathrm{~W}$ 


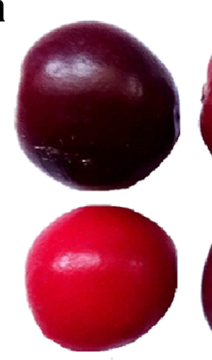

b
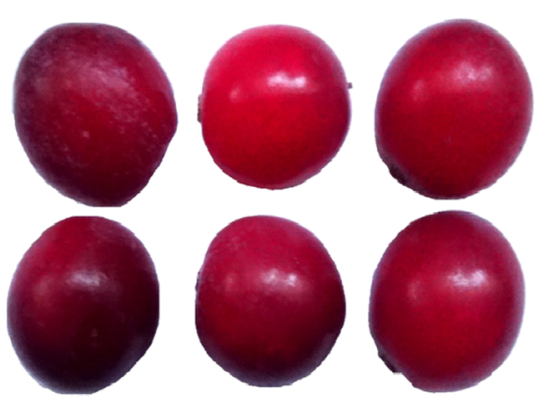

d
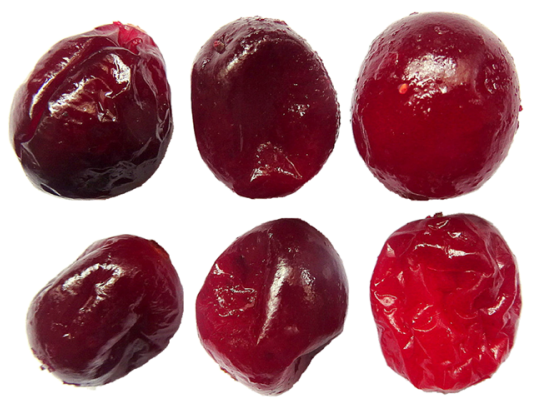

e
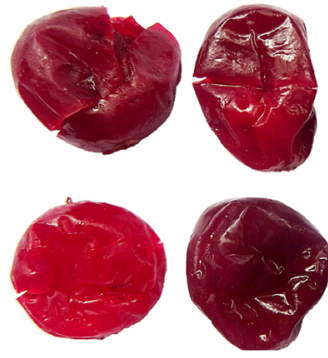
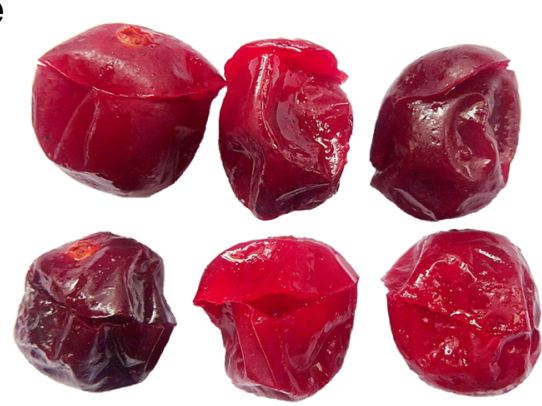

Fig. 5 Overall appearance of cranberries subjected to different initial pretreatments: (a) F; (b) FO; (c) FM1; (d) FM5; (e) FM8. F-frozen cranberries; FO - frozen cranberries subjected to osmotic dehydration; FM1O-frozen cranberries subjected to microwave vacuum pretreatment at microwave power of $100 \mathrm{~W}$ followed by osmotic dehydration; FM5O - frozen cranberries subjected to microwave vacuum pretreatment at microwave power of $500 \mathrm{~W}$ followed by osmotic dehydration; FM8O - frozen cranberries subjected to microwave vacuum pretreatment at microwave power of $800 \mathrm{~W}$ followed by osmotic dehydration

microwave power (FM5OM1 and FM8OM1). Higher lightness values in cranberries subjected to all drying treatments can probably be attributed to the loss of skin pigments, such as anthocyanins and phenolic compounds, which are water-soluble compounds (Wojdylo et al. 2009). In cranberries, most anthocyanins are found in hard fruit skins. Microwave-vacuum treatment, especially at higher power $(500 \mathrm{~W}$ and $800 \mathrm{~W}$ ), alters the structure of the skin which loses elasticity and becomes more susceptible to cracking as a result. For this reason, cranberries dried at higher microwave power were lighter than frozen berries (Table 7).

The value of parameter $a^{*}$ which, in its positive form, denotes the redness of the sample, is also an important quality indicator in fruit. The color of dried cranberries is determined mostly by red anthocyanins (mainly peonidin3-O-galactoside and cyanidin-3-O-galactoside) and yellow flavonoids (Leusink et al. 2010). The value of $a^{*}$ was higher in cranberries subjected to nearly all drying treatments than in frozen cranberries (Table 7). Parameter $a^{*}$ was determined at $6.0 \pm 0.6$ in frozen cranberries and at $5.9 \pm 0.5$ to $10.2 \pm 0.2$ in dried samples. Cranberries subjected to microwave-vacuum (FM1) and osmomicrowave-vacuum (FOM1) drying were as red as fresh cranberries, and their TMA values were even higher than in freeze-dried cranberries (Table 7). The $a^{*}$ values of microwave-vacuum pretreated cranberries (FM1OM1, FM5OM1, FM8OM1) did not differ significantly $(p \leq$ $0.05)$, but these samples were characterized by a greater 
Table 7 Effect of initial pretreatment on the color parameters and indices of cranberries subjected to different initial pretreatments

\begin{tabular}{|c|c|c|c|c|c|c|}
\hline \multirow[t]{2}{*}{ Method } & \multicolumn{3}{|c|}{ Color parameters } & \multicolumn{3}{|c|}{ Color indices } \\
\hline & $L^{*}[-]$ & $a^{*}[-]$ & $b^{*}[-]$ & $\Delta E^{*}[-]$ & $\Delta C^{*}[-]$ & $\Delta H^{*}[-]$ \\
\hline $\mathrm{F}$ & $30.8 \pm 0.3^{\mathrm{a}}$ & $6.0 \pm 0.6^{\mathrm{a}}$ & $2.4 \pm 0.2^{\mathrm{a}}$ & - & - & - \\
\hline FM1 & $32.0 \pm 0.2^{\mathrm{b}}$ & $6.8 \pm 0.5^{\mathrm{a}}$ & $4.1 \pm 0.2^{\mathrm{b}}$ & $2.2 \pm 0.6^{\mathrm{a}}$ & $0.4 \pm 1.2^{\mathrm{a}}$ & $1.8 \pm 1.7^{\mathrm{a}}$ \\
\hline FOM1 & $32.1 \pm 0.2^{\mathrm{b}}$ & $5.9 \pm 0.5^{\mathrm{a}}$ & $4.3 \pm 0.2^{\mathrm{b}}$ & $2.3 \pm 1.3^{\mathrm{a}}$ & $0.3 \pm 1.2^{\mathrm{a}}$ & $1.9 \pm 1.7^{\mathrm{a}}$ \\
\hline FM1OM1 & $33.9 \pm 0.4^{\mathrm{c}}$ & $9.2 \pm 0.2^{\mathrm{b}}$ & $5.4 \pm 0.2^{\mathrm{c}}$ & $5.4 \pm 1.7^{\mathrm{b}}$ & $0.9 \pm 1.4^{\mathrm{a}}$ & $4.4 \pm 2.0^{\mathrm{a}}$ \\
\hline FM5OM1 & $36.6 \pm 0.3^{\mathrm{e}}$ & $10.2 \pm 0.2^{b}$ & $4.5 \pm 0.2^{\mathrm{b}}$ & $7.4 \pm 0.6^{\mathrm{b}}$ & $0.9 \pm 1.2^{\mathrm{a}}$ & $4.6 \pm 1.8^{\mathrm{a}}$ \\
\hline FM8OM1 & $35.6 \pm 0.3^{\mathrm{d}}$ & $9.9 \pm 0.6^{\mathrm{b}}$ & $5.2 \pm 0.2^{\mathrm{c}}$ & $6.8 \pm 0.4^{\mathrm{b}}$ & $1.0 \pm 1.3^{\mathrm{a}}$ & $4.7 \pm 1.8^{\mathrm{a}}$ \\
\hline
\end{tabular}

Table shows the mean values \pm standard errors

Same letters in the same column mean that the mean values are not significantly different at a confidence level of $95 \%(p \leq 0.05)$

F-frozen cranberries; FM1 - frozen cranberries subjected to microwave vacuum drying at microwave power of $100 \mathrm{~W}$; FOM1-frozen cranberries subjected to osmotic dehydration and microwave vacuum drying at microwave power of $100 \mathrm{~W}$; FM1OM1 - frozen cranberries subjected to microwave vacuum pretreatment at microwave power of $100 \mathrm{~W}$ followed by osmotic dehydration and microwave vacuum drying at microwave power of $100 \mathrm{~W}$; FM5OM1 - frozen cranberries subjected to microwave vacuum pretreatment at microwave power of $500 \mathrm{~W}$ followed by osmotic dehydration and microwave vacuum drying at microwave power of $100 \mathrm{~W}$; FM8OM1 - frozen cranberries subjected to microwave vacuum pretreatment at microwave power of $800 \mathrm{~W}$ followed by osmotic dehydration and microwave vacuum drying at microwave power of $100 \mathrm{~W}$

contribution of redness than frozen cranberries (Table 7). In contrast, the TMA values of cranberries processed by FM1OM1, FM5OM1 and FM8OM1 were lower than in freeze-dried fruit (Table 7). This is not uncommon, and selected pretreatment and dehydration techniques can produce dried fruit that is redder than the control (fresh) sample. The above could point to the concentration of natural pigments during drying and intensification of red color (Chiralt and Talens 2005). The noted results can be also be attributed to lower oxygen availability and lower temperature during vacuum drying under low pressure. In these circumstances, the enzymatic browning reaction, which is the main cause of color degradation in dried samples, is relatively weak (Jiang et al. 2017). The reddening of cranberry skin during microwave drying could also result from changes in $\mathrm{pH}$ because the color of anthocyanins varies with $\mathrm{pH}$ and it can change by up to 3 units (Wojdylo et al. 2009). In acidic aqueous solutions, anthocyanins are represented by four structures that coexist in equilibrium: flavylium cation (red), quinoidal base (blue), carbinol pseudo-base (colorless) and chalcone (colorless or light yellow). Therefore, an increase in $\mathrm{H}^{+}$concentration during drying can shift the anthocyanin equilibrium towards the production of the flavylium cation, which may increase the contribution of redness. Rudy et al. (2015) found that the addition of L-ascorbic acid and citric acid increased the lightness and redness of dried pulped cranberries. Microwavevacuum dehydration at high microwave power (FM5OM1 and FM8OM1) caused significant structural changes in cranberry cells (numerous fissures and cracks), which led to the release of bound anthocyanins from the matrix and an increase in their availability. Therefore, despite the partial loss of anthocyanins during dehydration, some anthocyanins are retained in the skin at reduced concentrations. Furthermore, anthocyanins participate in polymerization or condensation reactions with tannins, other anthocyanins or flavonols, as well as in copigmentation reactions, which explains the decrease in the concentrations of anthocyanins that were diffused to the pulp (Marquez et al. 2014).

The value of parameter $b^{*}$ denoting yellowness or blueness generally increased in all dried cranberries. It was determined at $2.4 \pm 0.2$ in frozen samples and at $4.1 \pm 0.2$ to $5.4 \pm 0.2$ in dried samples. The contribution of yellowness was approximately twice higher in dried cranberries than in frozen fruit (Table 7). The greatest increase in $b^{*}$ values was found in cranberries subjected to microwave-vacuum pretreatment at higher microwave power before hybrid dehydration (FM1OM1, FM5OM1, FM8M1). Under the above drying conditions, red anthocyanin cations could be converted to colorless or yellow chalcones, and then to brown polymers. A similar dependency was observed by Ścibosz et al. (2010) in blueberries. The cited authors reported an increase in parameters $L^{*}$ and $b^{*}$ with an increase in processing time and temperature, which contributed to the lightness and the contribution of yellowness in dried fruit.

The dehydration process significantly influenced the values of $\Delta E^{*}$ and $\Delta H^{*}$ in cranberries. Values of $\Delta E^{*}$ higher than 5 indicate that dehydration of microwavevacuum treated cranberries induced changes that can be identified even by an inexperienced observer, whereas values close to 2 indicate that dehydration of untreated berries induced changes that cannot be identified even 
by an experienced observer. Dehydration did not influence the saturation of dried fruits. The overall appearance of dried and untreated berries is shown in Fig. 4.

\section{Conclusions}

Microwave-vacuum pretreatment accelerates mass transfer during osmotic dehydration of cranberries. Regardless of microwave power, this pretreatment should be applied before osmotic dehydration to promote dehydration and decrease impregnation. In microwave-vacuum pretreated samples, moisture loss and solids gain in equilibrium state were two or even three times higher than in untreated fruit. Microwave-vacuum pretreatment at higher microwave power (500 and $800 \mathrm{~W}$ ) significantly increased moisture diffusivity during osmotic dehydration of whole cranberries. The Weibull model well fit the observed data. Regardless of the type of pretreatment, a relatively long phase with a constant drying rate was followed by a relatively short phase with a decreasing drying rate during final microwave-vacuum drying of cranberries. The highest drying rate during the phase with a constant drying rate was observed in untreated berries. Variations in microwave power during microwave-vacuum pretreatment did not influence the drying rate of cranberries in the phase with a constant drying rate. Moisture diffusivity was higher in samples without microwave-vacuum pretreatment than in pretreated samples.

Microwave-vacuum drying and osmo-microwave-vacuum drying of frozen cranberries produces dried fruit of higher quality. These drying methods are also characterized by shorter processing times than freeze drying. However, cranberries subjected to microwave-vacuum pretreatment at low microwave power $(100 \mathrm{~W})$ before dehydration were also characterized by a high content of phenolic compounds, high levels of antioxidant activity and high concentrations of anthocyanins and flavonoids which contributed to the attractive color of the final product. The total polyphenol content of pretreated samples was similar to or higher than in freezedried cranberries. These results indicate that microwave-vacuum, osmo-microwave-vacuum and osmo-microwavevacuum drying combined with microwave-vacuum pretreatment at low microwave power $(100 \mathrm{~W})$ are equally or even more appealing methods of preserving whole cranberries than freeze drying.

Acknowledgements The authors would like to thank the National Science Centre in Poland for funding project no. 2015/17/B/NZ9/03601 entitled: "The effect of unconventional pretreatment methods on the kinetic of hybrid dehydration and physical and chemical properties of cranberries (Vaccinium macrocarpon)". The authors are also grateful to Marcin Turemko of the University of Warmia and Mazury in Olsztyn for providing technical support and performing TPC, TMA, TFC and FRAP analyses for the needs of this study.

Open Access This article is distributed under the terms of the Creative Commons Attribution 4.0 International License (http:// creativecommons.org/licenses/by/4.0/), which permits unrestricted use, distribution, and reproduction in any medium, provided you give appropriate credit to the original author(s) and the source, provide a link to the Creative Commons license, and indicate if changes were made.

\section{References}

Alasalvar, C., \& Shahidi, F. (2013). Dried foods: phytochemicals and health effects (pp. 101-132). Ames: Wiley-Blackwell.

Amami, E., Vorobiev, E., \& Kechaou, N. (2005). Effect of pulsed electric field on the osmotic dehydration and mass transfer kinetics of apple tissue. Drying Technology, 23(3), 581-595. https://doi.org/10.1081/ DRT-200054144.

Andrade, S. A. C., Neto, B. B., Nóbreg, A. C., Azoubel, P. M., \& Guerra, N. B. (2007). Evaluation of water and sucrose diffusion coefficients during osmotic dehydration of jenipapo (Genipa americana L.) Journal of Food Engineering, 78(2), 551-555. https://doi.org/10. 1016/j.jfoodeng.2005.10.023.

Assis, F. R., Morais, R. M. S. C., \& Morais, A. M. M. B. (2016). Mass transfer in osmotic dehydration of food products: comparison between mathematical models. Food Engineering Review, 8(2), 116133. https://doi.org/10.1007/s12393-015-9123-1.

Azuara, E., Beristain, C. I., \& Garcia, H. S. (1992). Development of a mathematical model to predict kinetics of osmotic dehydration. Journal of Food Science and Technology, 29, 239-242.

Beaudry, C., Raghavan, G. S. V., \& Rennie, T. J. (2003). Microwave finish drying of osmotically dehydrated cranberries. Drying Technology, 21(9), 1797-1810. https://doi.org/10.1081/DRT120025509.

Beaudry, C., Raghavan, G. S. V., Ratti, C., \& Rennie, T. J. (2004). Effect of four drying methods on the quality of osmotically dehydrated cranberries. Drying Technology, 22(3), 521-539. https://doi.org/10. 1081/DRT-120029999.

Benzie, I. F. F., \& Strain, J. J. (1999). Ferric reducing/antioxidant power assay: direct measure of total antioxidant activity of biological and modified version for simultaneous measurements of total antioxidant power and ascorbic acid concentration. Methods in Enzymology, 299, 15-27. https://doi.org/10.1016/S0076-6879(99) 99005-5.

Béttega, R., Rosa, J. G., Corrêa, R. G., \& Freire, J. T. (2014). Comparison of carrot (daucus carota) drying in microwave and in vacuum microwave. Brazilian Journal of Chemical Engineering, 31(2), 403412. https://doi.org/10.1590/0104-6632.20140312s00002668.

Bondaruk, J., Markowski, M., \& Błaszczak, W. (2007). Effect of drying conditions on the quality of vacuum-microwave dried potato cubes. Journal of Food Engineering, 81(2), 306-312. https://doi.org/10. 1016/j.jfoodeng.2006.10.028.

Borowska, E. J., Mazur, B., Gadzała Kopciuch, R., \& Buszewski, B. (2009). Polyphenol, anthocyanin and resveratrol mass fraction and antioxidant properties of cranberry cultivars. Food Technology and Biotechnology, 47(1), 56-61.

Brown, P. N., Murch, S. J., \& Shipley, P. (2012). Phytochemical diversity of cranberry (Vaccinium macrocarpon Aiton) cultivars by anthocyanin determination and metabolomics profiling with chemometric analysis. Journal of Agricultural and Food Chemistry, 60(1), 261271. https://doi.org/10.1021/jf2033335.

Chamorro, S., Goni, I., Viveros, A., Hervert-Hermandes, D., \& Brenes, A. (2012). Changes in polyphenolic content and antioxidant activity 
after thermal treatments of grape seed extract and grape pomace. European Food Research and Technology, 234(1), 147-155. https://doi.org/10.1007/s00217-011-1621-7.

Chiralt, A., \& Talens, P. (2005). Physical and chemical changes induced by osmotic dehydration in plant tissues. Journal of Food Engineering, 67(1-2), 167-177. https://doi.org/10.1016/j.jfoodeng. 2004.05.055.

Côté, J., Caillet, S., Doyon, G., Sylvain, J.-F., \& Lacroix, M. (2010). Bioactive compounds in cranberries and their biological properties. Critical Reviews in Food Science and Nutrition, 50(7), 666-679. https://doi.org/10.1080/10408390903044107.

Crank, J. (1975). The mathematics of diffusion (second ed.). London: Oxford University Press.

Cui, Z. W., Cai, M. Q., Song, C. F., Hilaire, N., \& Wang, Y. (2012). Effects of different pretreatments on dynamic countercurrent extraction of polysaccharides from Ganoderma. Separation and Purification Technology, 85, 61-68. https://doi.org/10.1016/j. seppur.2011.09.040.

Cunha, L. M., Oliveira, F. A. R., \& Oliveira, J. C. (1998). Optimal experimental design for estimating the kinetic parameters of process described by the Weibull probability distribution function. Journal of Food Engineering, 37(2), 175-191. https://doi.org/10.1016/ S0260-8774(98)00085-5.

Dak, M., \& Pareek, N. K. (2014). Effective moisture diffusivity of pomegranate arils undergoing microwave-vacuum drying. Journal of Food Engineering, 122, 117-121. https://doi.org/10.1016/j. jfoodeng.2013.08.040.

Ekezie, F. G. C., Sun, D. W., Han, Z., \& Cheng, J. H. (2017). Microwaveassisted food processing technologies for enhancing product quality and process efficiency: a review of recent developments. Trends in Food Science and Technology, 67, 58-69. https://doi.org/10.1016/j. tifs.2017.05.014.

Gacula Jr., M. C., \& Kubala, J. J. (1975). Statistical models for shelf life failures. Journal of Food Science, 40, 404-409.

Giri, S. K., \& Prasad, S. (2007). Drying kinetics and rehydration characteristics of microwave-vacuum and convective hot-air dried mushrooms. Journal of Food Engineering, 78(2), 512-521. https://doi. org/10.1016/j.jfoodeng.2005.10.021.

Grabowski, S., Marcotte, M., Quan, D., Taherian, A. R., Zareifard, M. R., Poirier, M., \& Kudra, T. (2007). Kinetics and quality aspects of Canadian blueberries and cranberries dried by osmoconvective method. Drying Technology, 25(2), 367-374. https://doi.org/10. 1080/07373930601120563.

Henderson, S. M., \& Pabis, S. (1961). Grain drying theory. I. Temperature effect on drying coefficient. Journal of Agricultural Engineering Research, 16(3), 169-174.

Herman-Lara, E., Martinez-Sanchez, C. E., Pacheco-Angulo, H., Carmona-Garcia, R., Ruiz-Espinosa, H., \& Ruiz-Lopez, I. I. (2013). Mass transfer modeling of equilibrium and dynamic periods during osmotic dehydration of radish in $\mathrm{NaCl}$ solutions. Food and Bioproducts Processing, 91(3), 216-224. https://doi.org/10.1016/j. fbp.2012.10.001.

Howard, L. R., Prior, R. L., Liyanage, R., \& Lay, J. O. (2012). Processing and storage effets on berry polyphenols: challenges and implications for bioactive properties. Journal of Agricultural and Food Chemistry, 60(27), 6678-6693. https://doi.org/10.1021/jf2046575.

Hutchings, J. B. (1999). Food color and appearance. Gaithersburg: Aspen Publishers. https://doi.org/10.1007/978-1-4615-2373-4.

Jia, Z., Tang, M., \& Wu, J. (1998). The determination of flavonoid contents in mulberry and their scavenging effects on superoxides radical. Food Chemistry, 64, 555-559.

Jiang, N., Liu, C., Li, D., Zhang, Z., Liu, C., Wang, D., Niu, L., \& Zhang, M. (2017). Evaluation of freeze drying combined with microwave vacuum drying for functional okra snacks: antioxidant properties, sensory quality, and energy consumption. LWT-Food Science and
Technology, 82, 216-226. https://doi.org/10.1016/j.lwt.2017.04. 015 .

Jiminez, N., Bohuon, P., Lima, J., Dornier, M., Vaillant, F., \& Perez, A. M. (2010). Kinetics of anthocyanin degradation and browning in reconstituted blackberry juice treated at hugh temperatures $(100$ $\left.180{ }^{\circ} \mathrm{C}\right)$. Journal of Agricultural and Food Chemistry, 58(4), 2314-2322. https://doi.org/10.1021/jf902381e.

Karel, M., \& Lund, D. B. (2003). Physical principles of food preservation (2nd ed.). New York: Marcel Dekker, Inc.. https://doi.org/10.1201/ 9780203911792

Kaymak-Ertekin, F., \& Sultanoglu, M. (2000). Modelling of mass transfer during osmotic dehydration of apples. Journal of Food Engineering, 46(4), 243-250. https://doi.org/10.1016/S0260-8774(00)00084-4.

Kowalski, S. J., Musielak, G., \& Banaszak, J. (2010). Heat and mass transfer during microwave-convective drying. AICHE Journal, $56(1), 24-35$.

Knorr, D. (2003). Impact of non-thermal processing on plant metabolites. Journal of Food Engineering, 56(2), 131-134. https://doi.org/10. 1016/S0260-8774(02)00321-7.

Knorr, D., Rastogi, N. K., \& Angersbach, A. (2000). Synergistic effect of high hydrostatic pressure pretreatment and osmotic stress on mass transfer during osmotic dehydration. Journal of Food Engineering, $45,25-31$.

Kwok, B. H. L., Hu, C., Durance, T., \& Kitts, D. D. (2004). Dehydration techniques affect phytochemical contents and free radical scavenging activities of Saskatoon berries (Amelanchier alnifolia Nutt). Journal of Food Science, 69, S122-S126.

Lee, J., Durst, R. W., \& Wrolstad, R. E. (2005). Determination of total monomeric anthocyanin pigment content of fruit juices, beverages, natural colorants, and wines by the $\mathrm{pH}$ differential method: collaborative study. Journal of AOAC International, 88(5), 1269-1278.

Leusink, G. J., Kitts, D. D., Yaghmaee, P., \& Durance, T. (2010). Retention of antioxidant capacity of vacuum microwave dried cranberry. Journal of Food Science, 75(3), C311-C316. https://doi.org/ 10.1111/j.1750-3841.2010.01563.x.

Lohachoompol, V., Srzednicki, G., \& Craske, J. (2004). The change of total anthocyanins in blueberries and their antioxidant effect after drying and freezing. Journal of Biomedicine and Biotechnology, 2004(5), 248-252. https://doi.org/10.1155/S1110724304406123.

Mancilla, Y. N., Won, M. P., Gálvez, A. V., Arias, V., Munizaga, G. T., Labarca, V. B., Mondaca, R. L., \& Scala, K. D. (2011). Modeling mass transfer during osmotic dehydration of strawberries under high hydrostatic pressure conditions. Innovative Food Science and Emerging Technologies, 12(3), 338-343. https://doi.org/10.1016/j. ifset.2011.03.005.

Marquez, A., Perez-Serratosa, M., Varo, M. A., \& Merida, J. (2014). Effect of temperature on the anthocyanin extraction and color evolution during controlled dehydration of Tempranillo grapes. Journal of Agricultural and Food Chemistry, 62(31), 7897-7902. https://doi. org/10.1021/jf502235b.

Mejia-Meza, E., Yanez, J. A., Davies, N. M., Rasco, B., Younce, F., Remsberg, C., \& Clary, C. (2008). Improving nutritional value of dried blueberries (Vaccinium corymbosum L.) combining microwave-vacuum, hot-air drying and freeze drying technologies. International Journal of Food Engineering, 4(5), 1-6.

Mercali, G. D., Marczak, L. D. F., Tessaro, I. C., \& Noreña, C. P. Z. (2011). Evaluation of water, sucrose and $\mathrm{NaCl}$ effective diffusivities during osmotic dehydration of banana (Musa sapientum, shum.) LWT Food Science and Technology, 44(1), 82-91. https://doi.org/ 10.1016/j.lwt.2010.06.011.

Ochoa-Martínez, C. I., Ramaswamy, H. S., \& Ayala-Aponte, A. A. (2007). ANN-based models for moisture diffusivity coefficient and moisture loss at equilibrium in osmotic dehydration process. Drying Technology, 25(5), 775-783. https://doi.org/10.1080/ 07373930701370159 . 
Pappas, E., \& Schaich, K. M. (2009). Phytochemicals of cranberries and cranberry products: characterization, potential health effects, and processing stability. Critical Reviews in Food Science and Nutrition, 49(9), 741-781. https://doi.org/10.1080/ 10408390802145377.

Pokharkar, S. M., \& Prasad, S. (1998). Mass transfer during osmotic dehydration of banana slices. Journal of Food Science and Technology, 35(4), 336-338.

Ramaswamy, H.S., Tola, Y. (2014). Energy considerations in osmotic dehydration. In Modern drying technology. Eds.: Tsotsas E., Mujumbar, A.S. Weinheim, Germany: WileyVCH Verlag GmbH \& Co. KGaA.

Rastogi, N. K., Raghavarao, K. S. M. S., Niranjan, K., \& Knorr, D. (2002). Recent developments in osmotic dehydration: methods to enhance mass transfer. Trends in Food Science and Technology, 13(2), 48-59. https://doi.org/10.1016/S0924-2244(02)00032-8.

Rizvi, S. S. H. (2005). Thermodynamic properties of foods in dehydration. In M. A. Rao, S. S. H. Rizvi, \& A. K. Datta (Eds.), Engineering properties of foods (3rd ed., pp. 39-326). New York: Marcel Dekker, Inc.. https://doi.org/10.1201/9781420028805.ch7.

Rudy, S., Dziki, D., Krzykowski, A., Gawlik-Dziki, U., Polak, R., Różyło, R., \& Kulig, R. (2015). Influence of pre-treatments and freeze-drying temperature on the process kinetics and selected physico-chemical properties of cranberries (Vaccinium macrocarpon Ait.) LWT Food Science and Technology, 63, 497503.

Sadilova, E., Stintzing, F. C., \& Carle, R. (2006). Thermal degradation of acylated and nonacylated anthocyanins. Journal of Food Science, 71(8), C504-C512. https://doi.org/10.1111/j.1750-3841.2006. 00148.x.

Sarkis, J. R., Jaeschke, D. P., Tessaro, I. C., \& Marczak, L. D. F. (2013). Effects of ohmic and conventional heating on anthocyanin degradation during the processing of blueberry pulp. LWT-Food Science and Technology, 51(1), 79-85. https://doi.org/10.1016/j.lwt.2012.10. 024.

Scaman, C. H., \& Durance, T. D. (2005). Combined microwave vacuum drying. Emerging technologies for food processing (pp. 507-530). London: Elsevier.

Ścibosz, I., Kalisz, S., \& Mitek, M. (2010). Termiczna degradacja antocyjanów owoców borówki wysokiej. ŻYWNOŚĆ. Nauka, Technologia, Jakość, 5(72), 56-66.

Sereno, A. M., Moreira, R., \& Martinez, E. (2001). Mass transfer coefficients during osmotic dehydration of apple in single and combined aqueous solutions of sugar and salt. Journal of Food Engineering, 47(1), 43-49. https://doi.org/10.1016/S0260-8774(00)00098-4.

Shahidi, F., \& Naczk, M. (1995). Methods of analysis and quantification of phenolic compounds. In F. Shahidi \& M. Naczk (Eds.), Food phenolic: sources, chemistry, effects and application (pp. 287293). Lancaster/Pensylvania: Technomic Publishing Company.

Shofian, N. M., Hamid, A. A., Osman, A., Saari, N., Anwar, F., Dek, M. S., \& Hairuddin, M. R. (2011). Effect of freeze drying on the antioxidant compounds and antioxidant activity of selected tropical fruits. International Journal of Molecular Sciences, 12(7), 46784692. https://doi.org/10.3390/ijms12074678.

Sogi, D. A., Siddiq, M., Griby, I., \& Dolan, K. D. (2013). Total phenolics, antioxidant activity and functional properties of "Tommy Atkins" mango peel and kernel as affected by drying methods. Food
Chemistry, 141(3), 2649-2655. https://doi.org/10.1016/j. foodchem.2013.05.053.

Souraki, B. A., Ghaffari, A., \& Bayat, Y. (2012). Mathematical modeling of moisture and solute diffusion in the cylindrical green bean during osmotic dehydration in salt solution. Food and Bioproducts Processing, 90(1), 64-71. https://doi.org/10.1016/j.fbp.2010.11. 015.

Tonon, R. V., Brabet, C., \& Hubinger, M. D. (2010). Anthocyanin stability and antioxidant activity of spray-dried acai (Euterpe oleracea mart.) juice produced with different carrier agents. Food Research International, 43(3), 907-914. https://doi.org/10.1016/j.foodres. 2009.12.013.

van der Sluis, A. A., Dekker M., \& van Boekel, M. A. (2005). Activity and concentration of polyphenolic antioxidants in apple juice. 3 . Stability during storage. Journal of Agricultral and Food Chemistry, 53(4), 1073-1080.

White, B. L., Howard, L. R., \& Prior, R. L. (2011). Impact of different stages of juice processing on the anthocyanin, flavonol, and procyanidin contents of cranberries. Journal of Agricultural and Food Chemistry, 59(9), 4692-4698. https://doi.org/10.1021/ jf200149a.

Wojdylo, A., Figiel, A., \& Oszmiański, J. (2009). Effect of drying methods with the application of vacuum microwaves on the bioactive compounds, color, and antioxidant activity of strawberry fruits. Journal of Agricultural and Food Chemistry, 57(4), 1337-1343. https://doi.org/10.1021/jf802507j.

Wojdylo, A., Figiel, A., Lech, K., Nowicka, P., \& Oszmiański, J. (2014). Effect of convective and vacuum-microwave drying on the bioactive compounds, color, and antioxidant capacity of sour cherries. Food. Bioprocess Technology, 7(3), 829-841. https://doi.org/10.1007/ s11947-013-1130-8.

Wray, D., \& Ramaswamy, H. S. (2015). Microwave-osmotic/microwavevacuum drying of whole cranberries: comparison with other methods. Journal of Food Science, 80(12), E-2792-EE2802.

Zielinska, M., \& Markowski, M. (2012). Color characteristics of carrots: effect of drying and rehydration. International Journal of Food Properties, 15(2), 450-466. https://doi.org/10.1080/10942912. 2010.489209.

Zielinska, M., \& Michalska, A. (2016). Microwave-assisted drying of blueberry (Vaccinium corymbosum L.) fruits: drying kinetics, polyphenols, anthocyanins, antioxidant capacity, colour and texture. Food Chemistry, 212(1), 671-680. https://doi.org/10.1016/j. foodchem.2016.06.003.

Zielinska, M., Ropelewska, E., \& Markowski, M. (2017). Thermophysical properties of raw, hot-air and microwave-vacuum dried cranberry fruits (Vaccinium macrocarpon L.) LWT - Food Science and Technology, 85, 204-211.

Zielinska, M., Sadowski, P., \& Błaszczak, W. (2015). Freezing/thawing and microwave-assisted drying of blueberries (Vaccinium corymbosum L.) LWT - Food Science and Technology, 62(1), $555-563$.

Zielinska, M., Zapotoczny, P., Alves-Filho, O., Eikevik, T. M., \& Błaszczak, W. (2013). Microwave vacuum assisted drying of green peas using heat pump and fluidized bed: a comparative study between atmospheric freeze drying and hot air convective drying. Drying Technology, 31(6), 633-642. https://doi.org/10.1080/ 07373937.2012 .751921 